\title{
Scheduling Electric Vehicle Charging to Minimise Carbon Emissions and Wind Curtailment
}

\author{
James Dixon, Waqquas Bukhsh, Calum Edmunds, Keith Bell \\ Dept. of Electronic and Electrical Engineering, University of Strathclyde, Glasgow, UK
}

\begin{abstract}
This paper presents an investigation of the potential for coordinated charging of electric vehicles to i) reduce the $\mathrm{CO}_{2}$ emissions associated with their charging by selectively charging when grid carbon intensity $\left(\mathrm{gCO}_{2} / \mathrm{kWh}\right)$ is low and ii) absorb excess wind generation in times when it would otherwise be curtailed. A method of scheduling charge events that seeks the minimum carbon intensity of charging while respecting EV and network constraints is presented via a time-coupled linearised optimal power flow formulation, based on plugging-in periods derived from a large travel dataset. Schedules are derived using real half-hourly grid intensity data; if charging in a particular event can be done entirely through use of renewable energy that would otherwise have been curtailed, its carbon intensity is zero. It was found that if 'dumb' charged from the current UK mainland (GB) grid, average emissions related to electric vehicle $(\mathrm{EV})$ charging are in the range $35-56 \mathrm{gCO}_{2} / \mathrm{km}$; this can be reduced to $28-40 \mathrm{gCO}_{2} / \mathrm{km}$ by controlled charging - approximately $20-30 \%$ of the tailpipe emissions of an average new petrol or diesel car sold in Europe. There is potential for EVs to absorb excess wind generation; based on the modelled charging behaviour, 500,000 EVs (20\% of Scotland's current car fleet) could absorb around three quarters of curtailment at Scotland's largest onshore wind farm.
\end{abstract}

Keywords: Electric vehicles, Renewable energy, Carbon intensity, Optimisation, Scheduling

1 Nomenclature

2 Sets

${ }_{3} \mathcal{B} \quad$ Buses, indexed by $b$ 
${ }_{4} \mathcal{D} \quad$ Domestic loads, indexed by $d$

${ }_{5} \mathcal{E} \quad$ Electric vehicle charging events, indexed by $e$

$6 \mathcal{G} \quad$ Grid supply points, indexed by $g$

${ }_{7} \mathcal{H}_{b} \quad$ Households connected to bus $b$

${ }_{8} \mathcal{L} \quad$ Lines, indexed by $l$

$9 \mathcal{T}$ Time horizon comprised of ten-minutely timesteps, indexed by $\tau$

${ }_{10} \mathcal{V}_{h} \quad$ Set of electric vehicles at household $h$, indexed by $v$

11 Parameters

${ }_{12} \mathrm{~B}_{l} \quad$ Susceptance of line $l$

${ }_{13} \mathrm{E}_{e}^{\max } \quad$ Battery capacity in EV for charge event $e$

${ }_{14} \mathrm{E}_{e}^{\mathrm{start}} \quad$ Energy storage content of EV at start of charge event $e$

${ }_{15} \mathrm{E}_{e}^{\mathrm{end}} \quad$ Energy storage content of EV at end of charge event $e$

${ }_{16} \mathrm{P}_{d, \tau}^{\mathrm{D}} \quad$ Active power demand from domestic load $d$ in time period $[\tau, \tau+1]$

${ }_{17} \mathrm{P}_{e, \tau}^{\mathrm{E}} \quad$ Active power demand from charge event $e$ in time period $[\tau, \tau+1]$

${ }_{18} \mathrm{P}_{e}^{\max } \quad$ Max. charging power for $\mathrm{EV}$ in charge event $e$

${ }_{19} \mathrm{~S}_{l}^{\max } \quad$ Active power capacity of a line $l$

${ }_{20} \mathrm{~V}^{\mathrm{D}} \quad$ Value of lost domestic load

${ }_{21} \mathrm{~V}^{\mathrm{E}} \quad$ Value of lost EV charging load

$22 \quad$ Cost of carbon emissions 


\begin{tabular}{|c|c|c|}
\hline 23 & Variables & \\
\hline 24 & $c_{g, \tau}^{\mathrm{G}}$ & Carbon intensity of grid supply point $g$ at timestep $\tau$ \\
\hline 25 & $d E_{e}^{\mathrm{LHS}}$ & Energy to be trimmed from beginning of charge event $e$ \\
\hline 26 & $d E_{e}^{\mathrm{RHS}}$ & Energy to be trimmed from end of charge event $e$ \\
\hline 27 & $E_{e, \tau}$ & Energy storage content of $\mathrm{EV}$ in charge event $e$ at timestep $\tau$ \\
\hline $\begin{array}{l}28 \\
29\end{array}$ & $p_{d, \tau}^{\mathrm{D}}$ & $\begin{array}{l}\text { Active power delivered to domestic demand } d \text { during time period } \\
{[\tau, \tau+1]}\end{array}$ \\
\hline 30 & $p_{e, \tau}^{\mathrm{E}}$ & Active power delivered to an $\mathrm{EV} e$ during time period $[\tau, \tau+1]$ \\
\hline 31 & $p_{g, \tau}^{\mathrm{G}}$ & Active power from grid supply point $g$ during time period $[\tau, \tau+1]$ \\
\hline 32 & $p_{l, \tau}^{\mathrm{L}}$ & Active power flow on line $l$ during time period $[\tau, \tau+1]$ \\
\hline 33 & $S o C_{e, \tau}$ & State of charge (per unit) of $\mathrm{EV}$ in charge event $e$ at timestep $\tau$ \\
\hline $\begin{array}{l}34 \\
35\end{array}$ & $t_{e}^{s}, t_{e}^{s^{\prime}}$ & $\begin{array}{l}\text { Original start time of charge event } e \text {, adjusted start time of charge } \\
\text { event } e\end{array}$ \\
\hline $\begin{array}{l}36 \\
37\end{array}$ & $t_{e}^{d}, t_{e}^{d^{\prime}}$ & $\begin{array}{l}\text { Original departure time of charge event } e \text {, adjusted departure } \\
\text { time of charge event } e\end{array}$ \\
\hline \multicolumn{3}{|c|}{$t_{e}^{\gamma_{e}}, t_{e}^{\infty}, t_{e}^{\min }$} \\
\hline $\begin{array}{l}39 \\
40 \\
41\end{array}$ & & $\begin{array}{l}\text { Time at which the EV's SoC reaches } \gamma_{e} \text { in charge event } e \text {, time } \\
\text { at which the charging power reaches } 1 \% \text { of the maximum rated } \\
\text { power in charge event } e \text {, minimum of } t_{e}^{d} \text { and } t_{e}^{\infty}\end{array}$ \\
\hline 42 & $\delta_{b, \tau}$ & Voltage angle at bus $b$ during time period $[\tau, \tau+1]$ \\
\hline $\begin{array}{l}43 \\
44\end{array}$ & $\gamma_{e}$ & $\begin{array}{l}\text { SoC at which the charging profile transitions from the constant } \\
\text { current to the constant voltage region in charge event } e\end{array}$ \\
\hline 45 & $\lambda_{e}$ & Decay constant of charging power applied during charge event $e$ \\
\hline
\end{tabular}


47

48

49

50

51

Abbreviations

BM Balancing mechanism

CC Constant current

CV Constant voltage

CP Convex programming

ESO Electricity system operator

EV Electric vehicle

GB Great Britain (referring to the largest island of the UK)

GIS Geographical information systems

MILP Mixed integer linear programming

NTS National Travel Survey

OA Output Area

RES Renewable energy sources

SoC State of charge (of an EV's battery)

V2G Vehicle to grid

\section{Introduction}

\subsection{Motivation}

The transport sector made up a quarter - 8 Gigatonnes - of total worldwide $\mathrm{CO}_{2}$ emissions in 2016, over three quarters of which were from road vehicles [1]. The World Health Organization estimates that 9 out of 10 people worldwide are living under air that breaches safe limits [2]. While the phasing out of fossil-fuelled vehicles in favour of plug-in battery electric vehicles $(\mathrm{EVs})$ is cited as a key part of the solution to both the decarbonisation of the sector and the improvement of air quality by governments worldwide from the UK [3] to China [4], Japan [5] and the USA [6], there has been resistance to their adoption. Some of this has been due to the impression 
that when charged from the power grid with its generation mix and associated carbon intensity, EVs do not offer any significant improvement in the carbon emissions. This is perpetuated by studies such as [7] which claims that, if charged from the German electricity system, electric vehicles (EVs) are no 'cleaner' than diesel-powered vehicles. While the methods used in [7] are under scrutiny and it has been shown in [8] that EVs have lower associated carbon emissions than internal combustion engine vehicles when charged from the electricity grids in any European Union member state, the associated carbon emissions of EV charging should not be neglected. It is suggested that the inherent flexibility of EV charging, given that the average private car in the UK spends $96 \%$ of its time parked [9], has the potential to interact positively with the grid in a way that optimises the use of renewable energy sources (RES). This paper presents an investigation of the potential for EVs to i) reduce the $\mathrm{CO}_{2}$ emissions associated with their charging by selectively charging when grid carbon intensity $\left(\mathrm{gCO}_{2} / \mathrm{kWh}\right)$ is low and ii) assist in further 'greening' the grid by using excess wind generation in times when it would otherwise be curtailed due to lack of local demand and transmission capacity to transport the power elsewhere.

\subsection{Relevant Literature}

The works reviewed in this section employ a wide range of techniques to examine the potential integration of RES and EV charging via mathematical optimisation. No matter the approach, they can be broadly divided into three areas based on the objective function to be optimised: the maximisation of RES output, the minimisation of RES curtailment (it is noted that while framed differently, these two points are analogous) or the minimisation of the associated carbon intensity of EV charging.

Works presented in [10], [11] and [12] all act to maximise RES output within the setting of a microgrid or EV charging car park: effectively a singlebus system with both RES generators and EV charging demand. In [10], the authors present a mixed integer linear programming (MILP) approach to minimise the total cost of supplying demand, given a time-varying generation mix with intermittent RES output and a fixed assumption of the number of EVs that make available a certain proportion of their batteries to be used in a bidirectional energy exchange (also known as 'Vehicle 2 Grid' (V2G)). Studies in [12] and [11] both present concepts of a charging station, where EVs must queue to charge. While the methods used are different - the authors in 
[12] formulate a Lyapunov optimisation, whereas a Markov decision processbased approach is used in [11] - the objective functions in both papers are formulated such that they are rewarded with increased use of RES (through there being a lower cost of 'dispatch') and penalised with a longer queue length. Whereas these microgrid/charging car park concepts certainly have their applications, they are not suitable for the study of widespread EV charging as the majority of which is expected to occur at private residencies [13]. In [14], the authors use a MILP approach to simulate the operation of an aggregator who is acting on the behalf of all EVs in a test network to ensure they receive a pre-arranged quantity of energy during the time during which the vehicle is available, subject to network constraints. The aggregator's objective is to minimise their own cost of buying energy for the charging of EVs, which is at a minimum during times of maximum RES output. While this approach is potentially an accurate reflection of how large-scale demand response from EVs may arise, the study in [14] uses overly simplistic assumptions as to when the EVs are plugged in and available, based on a small survey in one town made by the authors. On the contrary, work presented in this paper uses analysis from a large travel dataset to derive individuals' likely charging behaviour based on the energy requirements of their travel habits.

In [15], the potential reduction in curtailment of wind energy generation is calculated based on a future projection of the Danish energy system in which $8 \mathrm{GW}$ of wind power is installed and there are 500,000 EVs. All EVs in the system are aggregated to form one charging profile, based on a simple assumption relating to typical commuting patterns. By controlling the charging load via a heuristic method that seeks to maximise the utilisation of wind power by charging, it is reported that curtailment can be reduced by $20 \%$. Furthermore, [15] reports that the additional reduction in curtailment from $\mathrm{V} 2 \mathrm{G}$ approaches is insignificant, the total reduction from a controlled V2G approach being $21 \%$. In [16], the authors present analysis of the ability to reduce wind curtailment of six separate heuristic-based strategies for controlled EV charging, reporting a reduction of wind curtailment from $13 \%$ to $51 \%$ depending on the type of approach used. All strategies are tested on the concept of a 'nationwide battery' active during the assumed charging period of 23:00-07:00, i.e. an aggregation of all the hypothetical EVs served by the Dutch energy system - whose energy requirements are based on average travel behaviour in the Dutch national travel survey - into one flexible demand, similarly to the aggregation technique used in [15]. In [17], 
the authors present optimisation of a MILP problem to minimise the cost of generation given an availability of wind resource (with an associated dispatch cost of zero) and a flexible EV charging demand. While the modelling of EV charging demand in [17] is more sophisticated than in the aforementioned works, based on five different hypothetical archetypes of EV charging relating to the speed at which the vehicles are to be charged, the model uses a single aggregated load accounting for the total annual energy demand from all of Germany's projected 2030 EV fleet, an approach that fails to reflect the diversity in drivers' travel patterns and lacks detail compared with the individual travel diary approach proposed in this paper.

Works that focus specifically on the carbon intensity of charging are rarer than those that fit into the categories discussed in the preceding two sections. In [18], the authors establish the likely carbon intensity of EV charging given the average intensity $\left(\mathrm{gCO}_{2} / \mathrm{kWh}\right)$ of the Danish electricity grid, though there is no consideration of the flexibility of EV charging or scheduling of the charging load. The study in [19] is similar but based on the GB electricity system. Though the temporal variation in EV charging demand is considered, it is assumed that an increase in demand as a result of EV charging will be met by dispatchable generation and thus the resulting carbon intensity of EV charging is equal to the carbon intensity of the dispatchable energy capacity at a given time. Given the context of the GB system, this is composed of gas and coal plants. In [20], the authors propose a convex programming (CP) method to schedule EV charging to occur at the time of minimum grid carbon intensity. In common with [14-17], it is suggested that the assumptions regarding vehicles' travel patterns are overly simplistic: it is assumed that all vehicles are present between 17:00 and 08:00 the following morning, based on the authors' interpretation of a 'typical' working day. Furthermore, the focus on plug-in hybrid EVs with battery capacities around $5 \mathrm{kWh}$ limits the effect that controlled charging can have, as the total flexibility is less than if pure battery EVs with considerably larger battery capacities - such as in this paper - are used. Although the primary goal in [17] is to maximise the utilisation of wind power, it also presents the subsequent reduction in carbon intensity of charging as a result of the optimisation; however, the results are based on a constant grid intensity rather than a time series as presented in this paper. 


\subsection{Contribution}

A review of the relevant literature (section 1.2) has shown that while this area of research is already well practised, there remain gaps in the collective knowledge. This paper seeks to address these gaps as follows.

Firstly, whereas all of the works reviewed in section 1.2 use simplistic assumptions regarding the temporal variation in EVs' availability based on impressions of 'typical' driving patterns, this work uses a detailed simulation of the possible plugging in habits of a representative fleet of EVs, using two different models of charging behaviour to cover the possible spread in charging event frequency and energy requirement.

Secondly, all but one of the works reviewed assume a constant grid carbon intensity (the exception being [20], though they use a profile for only one day, neglecting considerable day-to-day and seasonal variation resulting from variations in demand and RES output). On the other hand, this work uses half-hourly grid intensity data from the GB electricity system operator (ESO) National Grid [21], and half-hourly curtailment data from Whitelee wind farm [22], a large (539 MW) transmission-connected wind farm that is nearby $(<15 \mathrm{~km})$ to the simulated distribution network.

Thirdly, all the works reviewed consider fixed EV parameters, such as the battery capacity and the charger power rating. However, it has been found that this affects individuals' charging habits: for instance, in the Electric Nation ${ }^{1}$ EV trial that concluded in July 2019 [23] it was found that drivers of EVs with larger battery capacities $(>35 \mathrm{kWh})$ are likely to charge less often - on average, 2-3 times per week - compared to drivers of EVs with smaller batteries $(<10 \mathrm{kWh})$ - on average, 5-6 times per week. These charging behaviours determine the flexibility of EV charging and the times at which the EVs are available to be charged. Consideration of these parameters is therefore important; this work includes parametric study of how battery capacity and charger power are likely to affect the ability of smart charging to reduce the carbon intensity associated with EV driving.

The rest of this paper is organised as follows. Section 2 describes how a model of a real distribution network is used to instantiate a fleet of EVs with representative week-long travel diaries assigned to them from a large

${ }^{1}$ The publicly-funded Electric Nation EV trial took place from January 2017 to December 2018 across various regions in the UK to provide data on EV charging habits for 673 vehicles comprising of 40 different models. 
travel dataset. Section 3 describes how EV charge events 'flexibility windows' are derived from this fleet of EVs. Section 4 describes how grid carbon intensity and wind curtailment are modelled. Section 5 describes how the EVs' charging is optimised to i) reduce the associated $\mathrm{CO}_{2}$ emissions of their charging and ii) reduce curtailment of Whitelee wind farm. Section 6 presents the results for both studies. Conclusions and suggestions of further work from this paper are made in section 7 .

\section{Distribution Network and EV Fleet Modelling}

This section describes the method used to derive sets of EV charge events based on the likely car-based transport energy requirements of residents served by a given electricity network. To do this, geographical information systems (GIS) data of a real distribution network is aligned with GIS data from the 2011 UK Census to map the demographics of the area covered by the network; in particular, the spatial distribution of vehicles within the network and the indicative travel habits of the individuals who drive them. Each vehicle is assigned a seven-day travel diary from the UK National Travel Survey (NTS) based on the employment type and means of travel to work of the driver. Using a heuristic method originally presented in [24], charging schedules are derived using two models of charging behaviour designed to cover the possible range of frequency and duration of charge events.

\subsection{Glasgow Southside Distribution Network}

The network model used to instantiate a fleet of EVs and to set constraints on their charging is derived from a real distribution network in the residential-dominated Southside area of Glasgow, UK. The network consists of a secondary $(11 / 0.4 \mathrm{kV})$ substation and three $0.4 \mathrm{kV}$ distribution feeders. The network serves 157 households, spread amongst 47 endpoints (i.e. there are some address points that are apartment blocks with multiple households). It is assumed that the different households are equally divided among the three phases and that those phases are balanced. Figure 1 shows a plot of the network topology with the location of the grid connection highlighted (left) and a rendered 3D image of the area in question (right) - imagery from Google Maps [25]. 


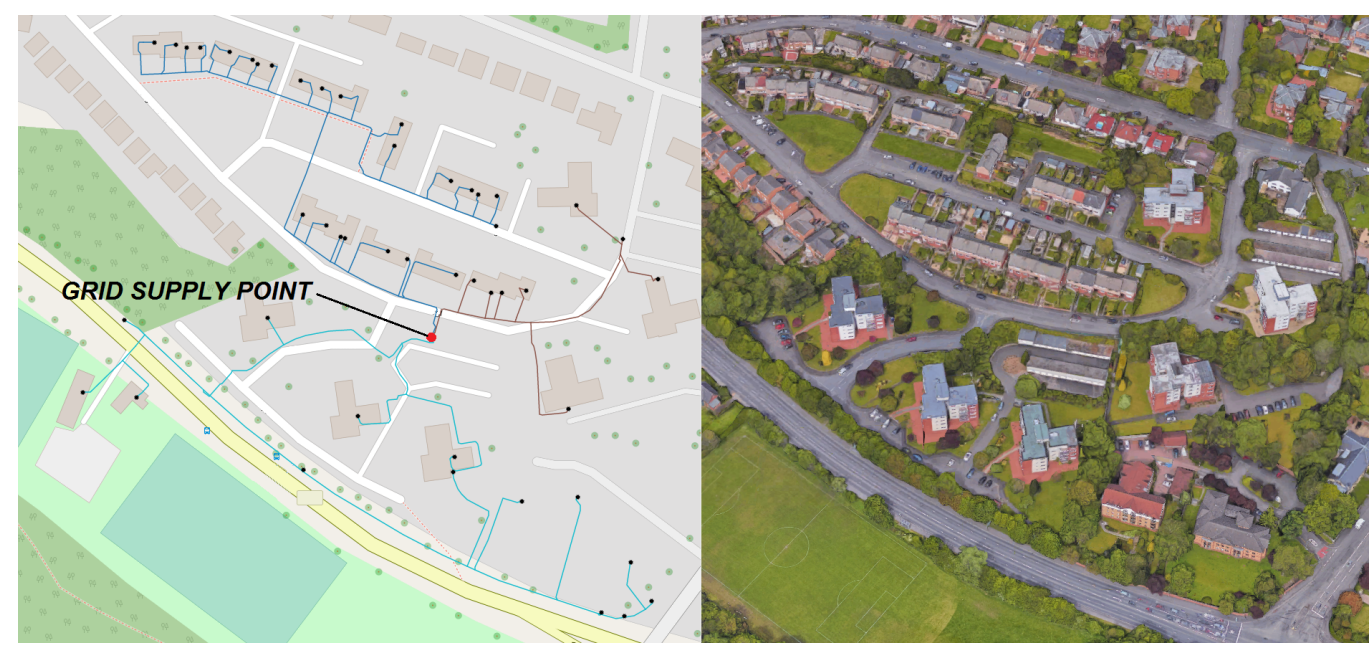

Figure 1: Glasgow Southside network used for instantiation of EV fleet (left) and rendered $3 \mathrm{D}$ image of area in question (right)

\subsection{Integration of Network Model with UK Census Data and National Travel Survey Travel Diaries}

In this study, a Monte Carlo-style approach is used to model uncertainties surrounding i) the demographics of the neighbourhood served by the network (Figure 1) - including the number of vehicles per household - and ii) the charging habits of the drivers of those vehicles.

\subsubsection{UK National Travel Survey Travel Diaries}

The UK NTS is conducted annually for around 15,000 residents in which they record all trips taken over a 7-day period [26]. The 7-day period recorded differs between the individuals recording the data, hence minimising any bias from seasonal effects and holidays. The resulting dataset for the years 20022016 as used in this study contains details of 2,042,058 car-based trips split between 126,186 week-long travel diaries, which have been aligned such that they all take place from 00:00 on Monday to 23:59 on Sunday. An example NTS travel diary is shown in Table 1. 
Table 1: Example UK NTS travel diary (car-based trips)

\begin{tabular}{llllll}
\hline $\begin{array}{l}\text { Trip } \\
\#\end{array}$ & Origin & Destination & Trip Start & Trip End & $\begin{array}{l}\text { Distance } \\
\text { (miles) }\end{array}$ \\
\hline 1 & Home & Food shop & Tu 09:30 & Tu 09:50 & 3 \\
2 & Food shop & Home & Tu 10:40 & Tu 11:00 & 3 \\
3 & Home & Other escort & Tu 18:15 & Tu 18:20 & 0.25 \\
4 & Other escort & Home & Tu 18:20 & Tu 18:25 & 0.25 \\
5 & Home & Other escort & Tu 19:40 & Tu 19:45 & 0.25 \\
6 & Other escort & Home & Tu 19:50 & Tu 19:55 & 0.25 \\
7 & Home & Food shop & W 09:30 & W 09:50 & 3 \\
8 & Food shop & Home & W 10:30 & W 10:45 & 3 \\
9 & Home & Work & Su 07:40 & Su 08:00 & 7 \\
10 & Work & Home & Su 17:00 & Su 17:20 & 7 \\
\hline
\end{tabular}

Aside from filling in a travel diary, NTS respondents also answer some questions about themselves. In this study, the travel diaries are disaggregated on the basis of the individual's employment type (employed, unemployed or self-employed) and their means of travel to work (car driver, car passenger, train, bus, bicycle, walk or N/A - i.e. unemployed/works from home). In accordance with UK Census data of the same fields, this is used to assign travel diaries to the fleet of EVs instantiated in the network that are likely to represent the travel habits of the individuals served by that network.

\subsubsection{UK Census Data}

The last completed Census in the UK was in 2011. The questions as used in this study are i) the number of vehicles at the household $(0-4+)$, and ii) the employment type/means of travel to work (if applicable) - for example (employed, car driver), (self-employed, train) or (unemployed, N/A). Each busbar in the network is matched with its corresponding output area (OA), the smallest unit of Census data available covering approx. 50 households, and hence distributions of responses to these two Census questions are returned. These distributions are used in a Monte Carlo-style approach (Algorithm 1) to instantiate a fleet of EVs and assign them with travel diaries - which, as already mentioned, have been disaggregated on the same basis that are likely to represent the travel habits of the local population.

\subsubsection{Instantiation of EV Fleet in Network}

The network data and Census data are combined to create a fleet of EVs as described in Algorithm 1. 


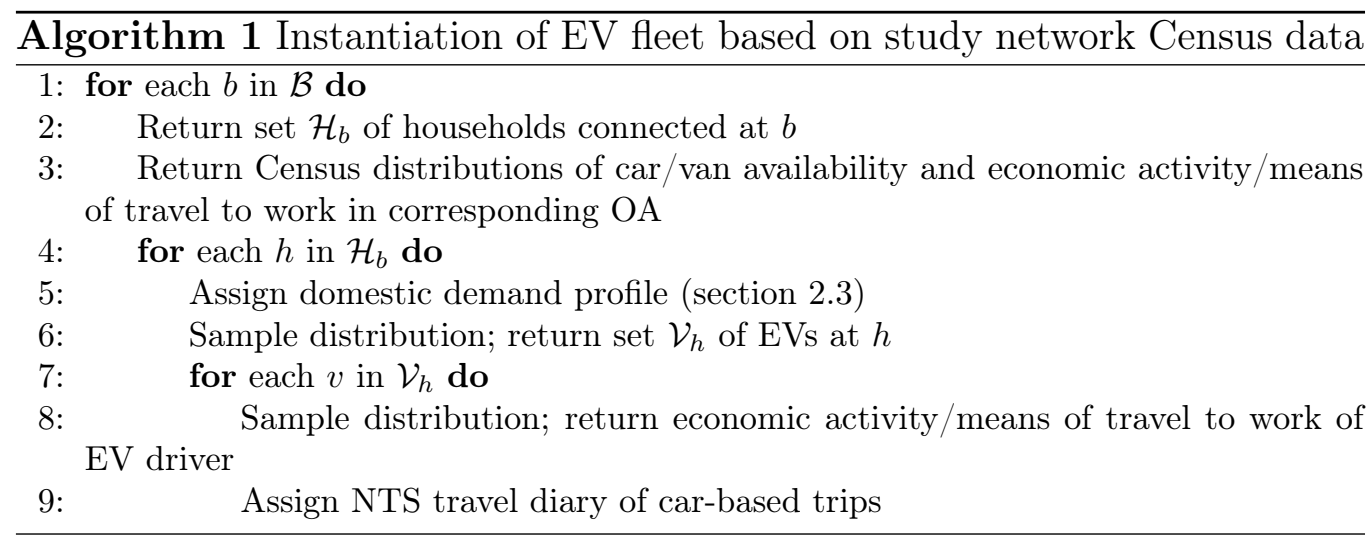

The approach in Algorithm 1 is repeated as a Monte Carlo-style simulation for 100 trials. This is described further in section 4.1.

\subsection{Domestic Demand Modelling}

It is assumed in this study that domestic demand (i.e. that which exists before the introduction of EVs) has zero flexibility. In this study, a higherorder Markov chain based household energy demand model from [27] is used to synthesise likely demand profiles for the domestic premises in the distribution network. The model simulates household electricity demand based on the active occupancy of households, derived from analysis of the results of the UK Time Use Survey - a large-scale household survey of more than 20,000 individuals that aims to shed light on how people in the UK spend their time [28]. The reader is directed to [27] for detailed information on the domestic demand tool used in this study. Figure 2 shows the simulated domestic demand for all households in this network for 100 trials, whereby each trial represents the establishment of household characteristics as per Algorithm 1. All trials were based on a winter weekday, as to reflect the peak demand on the system and the 'worst case' as planned for by the distribution network operator. 


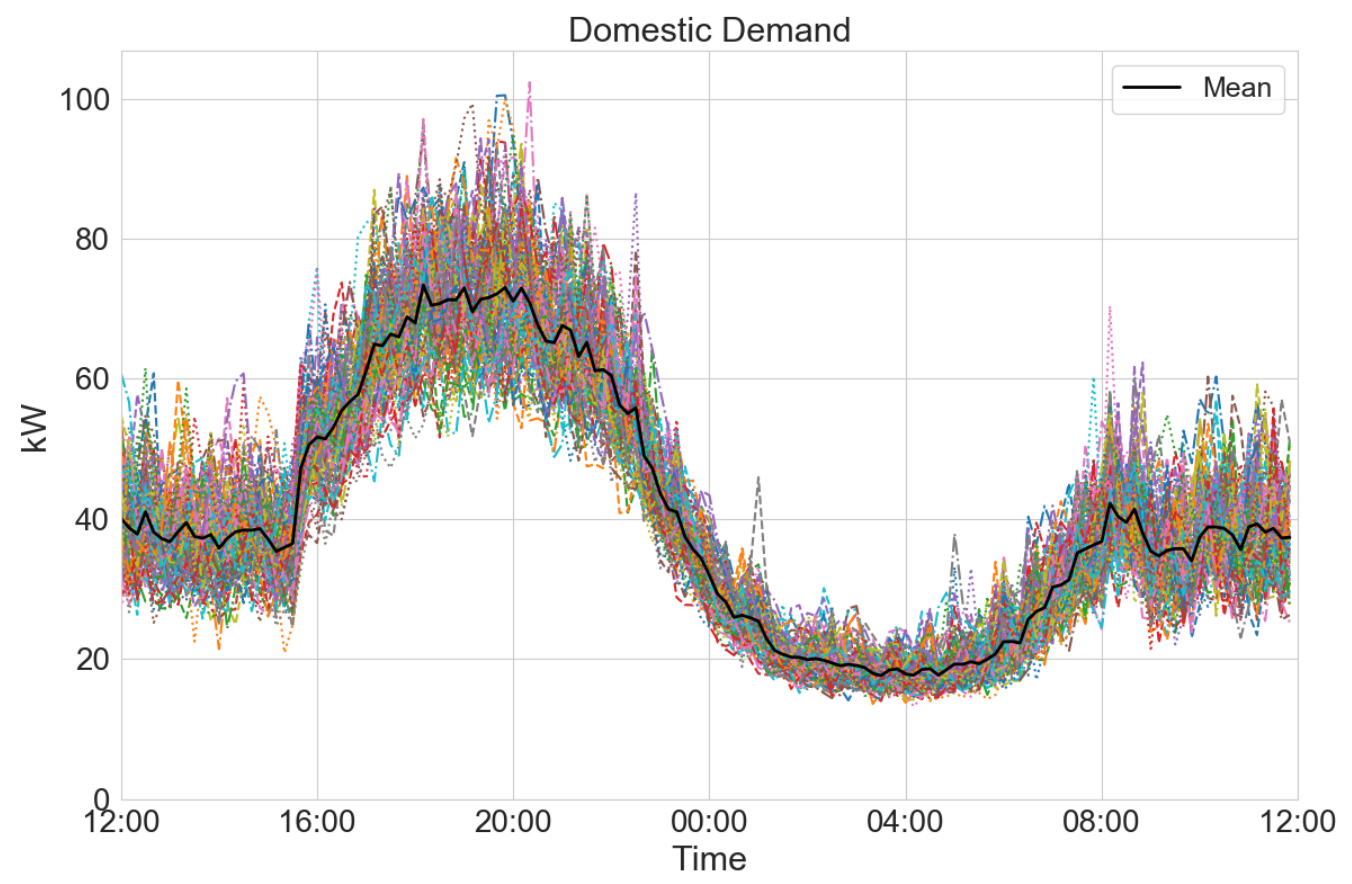

Figure 2: Domestic demand (kW) simulated for study network, 100 trials - mean demand across all trials shown as a black solid line

\section{Electric Vehicle Charge Event Modelling}

One of the most challenging aspects regarding modelling future electrified transport scenarios is the impact of human behaviour, including how individuals decide to schedule charge events. The frequency and duration of charge events, in addition to their energy requirement, determines the flexibility of EV charging and the extent to which their charging can be managed to seek the optimisation of some objective function.

Two methods are used to derive schedules of charge events from the NTS travel diaries (e.g. Table 1), designed to represent the spectrum of likely charging behaviours. These methods are described in sections 3.1-3.2.

\subsection{Minimal Charging Schedules}

The minimal charging schedules represent a scenario in which EV charging is seen by users as an inconvenience, and therefore something that they would aim to minimise. They are derived using a heuristic originally presented in the author's earlier work [24]. In summary, the method returns 
the minimum number of charge events required to satisfy the energy requirements of an NTS travel diary (Table 1), choosing parked charging events first and resorting to en route charging events only when parked charging opportunities are not sufficient to meet the travel diary's energy requirements. This is done by ensuring that the vehicle's state of charge $(\mathrm{SoC})$ is always greater than or equal to a prescribed minimum; that which would give 25 $\mathrm{km}$ of remaining range on a 'combined' energy consumption rate, based on how far a prudent driver would be willing to drive before charging. While the EV will minimise the time spent en route charging, gaining only enough energy it needs to arrive at the end of the trip with the minimum permitted SoC, it will seek to gain the maximum it can from any parked charging event - subject to the charger power and a standard Lithium-ion battery charging curve as further discussed in section 3.4.

The reader is referred to [24] for a detailed explanation of how this heuristic works. As an example, Table 2 shows a schedule of the minimum number of charge events necessary to meet the energy demand of the travel diary shown in Table 1. The SoC with which the vehicle starts the travel diary is randomised between the prescribed minimum and $100 \%$. In this example case, it was randomised as $74 \%$.

Table 2: Minimal charging schedule derived from NTS travel diary in Table 1 for an EV with a battery capacity of $24 \mathrm{kWh}$ and a home charger rated at $3.7 \mathrm{~kW} \mathrm{AC,} 88 \%$ efficiency

\begin{tabular}{lllllll}
\hline $\begin{array}{l}\text { Trip } \\
\#\end{array}$ & $\begin{array}{l}\text { Charge } \\
\text { Type }\end{array}$ & Plug-in & Plug-out & $\begin{array}{l}E^{\text {start }} \\
(\mathbf{k W h})\end{array}$ & $\begin{array}{l}\mathrm{E}^{\text {end }} \\
(\mathbf{k W h})\end{array}$ & $\begin{array}{l}\mathrm{P}^{\max } \\
(\mathbf{k W})\end{array}$ \\
\hline 8 & home & W 10:45 & Su 07:40 & 8.44 & 24 & 3.26 \\
\hline
\end{tabular}

In Table 2, $\mathrm{E}^{\text {start }}$ and $\mathrm{E}^{\mathrm{end}}$ are the energy storage contents of the $\mathrm{EV}$ at the start and end of the charge events respectively. $\mathrm{P}^{\max }$ is the maximum rated $\mathrm{DC}$ power the $\mathrm{EV}$ can be charged at. Note that the $\mathrm{AC}$ charger rating (in this case, $3.7 \mathrm{~kW}$ ) is multiplied by a one-way $\mathrm{AC} / \mathrm{DC}$ converter efficiency of $88 \%$, in common with empirical results presented in [29].

Table 2 shows that the EV was able to charge sufficiently to meet the energy requirements of its travel diary with one parked charging event taken at home at the end of trip 8. Note that although the EV could have charged after trips 2, 4 and 6, the driver chose not to as they could defer their charging until later in the week, thus finishing the week's travel diary with the maximum possible SoC. 


\subsection{Routine Charging Schedules}

The routine charging schedules represents a scenario in which EV charging at home is seen to carry negligible inconvenience (i.e. it has become routine) such that vehicles are always plugged in on arrival at home, irrespective of their SoC. Therefore, this section presents a modification to the heuristic described in [24], in that an EV will always charge at home, regardless of its $\mathrm{SoC}$ or the energy demand of future trips. The routine schedule could represent a scenario where individuals are incentivised to plug their vehicles in, for example if they are to be used as a flexible resource for the benefit of the grid.

Table 3 shows a schedule of charge events produced using the routine charging method for the NTS travel diary in Table 1.

Table 3: Routine charging schedule derived from NTS travel diary in Table 1 for an EV with a battery capacity of $24 \mathrm{kWh}$ and a home charger rated at $3.7 \mathrm{~kW}$ AC, $88 \%$ efficiency

\begin{tabular}{lllllll}
\hline $\begin{array}{l}\text { Trip } \\
\#\end{array}$ & $\begin{array}{l}\text { Charge } \\
\text { Type }\end{array}$ & Plug-in & Plug-out & $\begin{array}{l}\mathrm{E}^{\text {start }} \\
\mathbf{( k W h})\end{array}$ & $\begin{array}{l}\mathrm{E}^{\mathrm{end}} \\
(\mathbf{k W h})\end{array}$ & $\begin{array}{l}\mathrm{P}^{\max } \\
\mathbf{( k W )}\end{array}$ \\
\hline 2 & home & Tu 11:00 & Tu 18:15 & 10.36 & 24 & 3.26 \\
4 & home & Tu 18:25 & Tu 19:40 & 23.86 & 24 & 3.26 \\
6 & home & Tu 19:55 & W 09:30 & 23.86 & 24 & 3.26 \\
8 & home & W 10:45 & Su 07:40 & 22.36 & 24 & 3.26 \\
\hline
\end{tabular}

In Table 3, the EV charges at all the opportunities it gets: in this example, whereas it did not charge after trips 4, 6 and 8 under the minimal scenario, it did charge after these trips in the routine scenario. As a result, its energy requirements for these charge events tends to be less. Given that the total charging time is dictated by the duration of the parking event, charging under the routine method of charge event scheduling is typically more flexible than charging under the minimal method.

\subsection{Validation against Electric Nation Trial Data}

As already mentioned in section 1.3, it was found in the Electric Nation trial that drivers with larger batteries are likely to plug in on fewer occasions. The data collected in the trial in terms of average charging frequency per day, as taken from [23], is shown on a scatter plot in Figure 3 along with the average home charging frequency per day for all trials of all vehicles simulated with the minimal charging model in this study for both $24 \mathrm{kWh}$ and $64 \mathrm{kWh}$ battery capacities. 


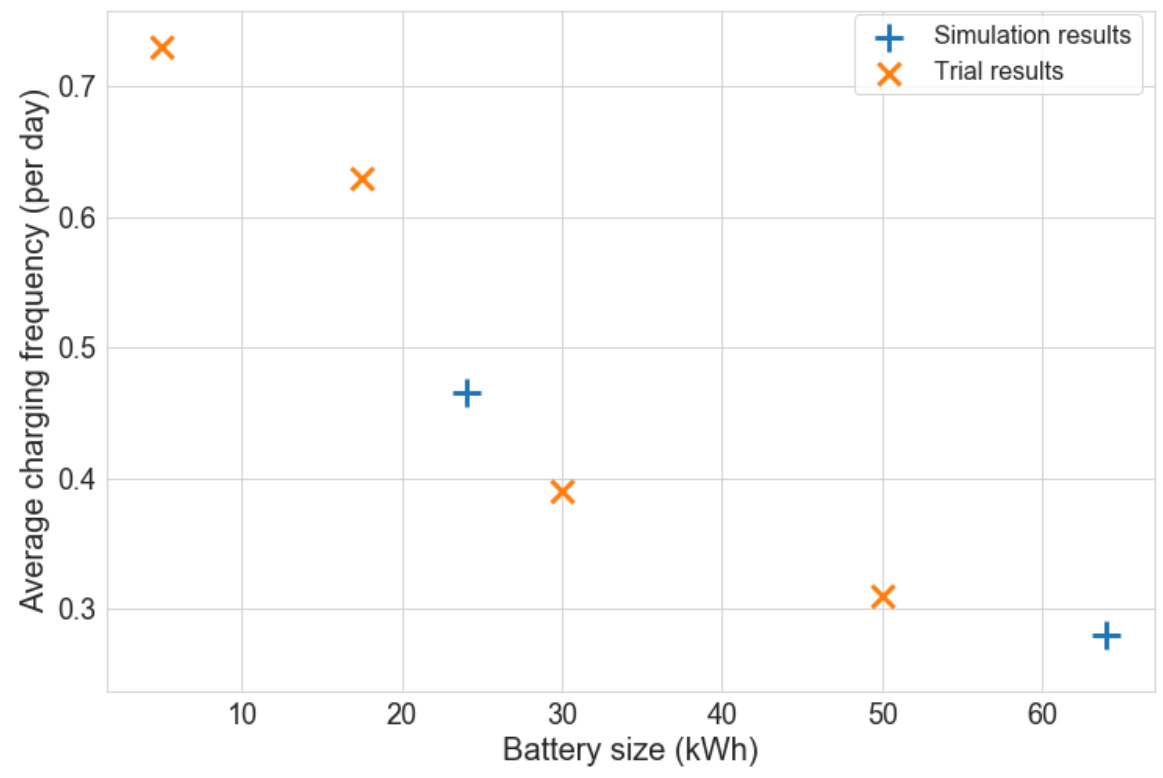

Figure 3: Scatter plot showing average charging frequency (events per day) against vehicle battery size for Electric Nation trial data and results from the simulation (minimal charging) in this study

Note that the battery sizes used for the Electric Nation data in Figure 3 are the midpoints of the intervals reported, e.g. where the project reported that EVs with batteries of 10-25 kWh charged on average 0.63 times per day, the corresponding value used for the figure is $17.5 \mathrm{kWh}$.

Figure 3 shows that the pattern of a reduction in charging frequency for increasing battery size holds true for the simulation in this study when using the minimal charging scenario. Note that when using the routine charging method, the frequency of home plugins will not change as drivers will always plug-in at home; their charging frequency will be equal to the average number of times they arrive at home in a day.

\subsection{Charging Flexibility Window}

The optimisation performed in this study is carried out on the basis of one 24 hour period in 10 minute timesteps, from midday to midday the next day. However, the charging schedules produced on the basis of a week-long travel 
diary are 7 days long. Therefore, the week-long charge schedules are trimmed accordingly to establish a 'flexibility window' for each charging event that fits into the 24 hour window of the optimisation study. The process by which this is done is illustrated in Figure 4.

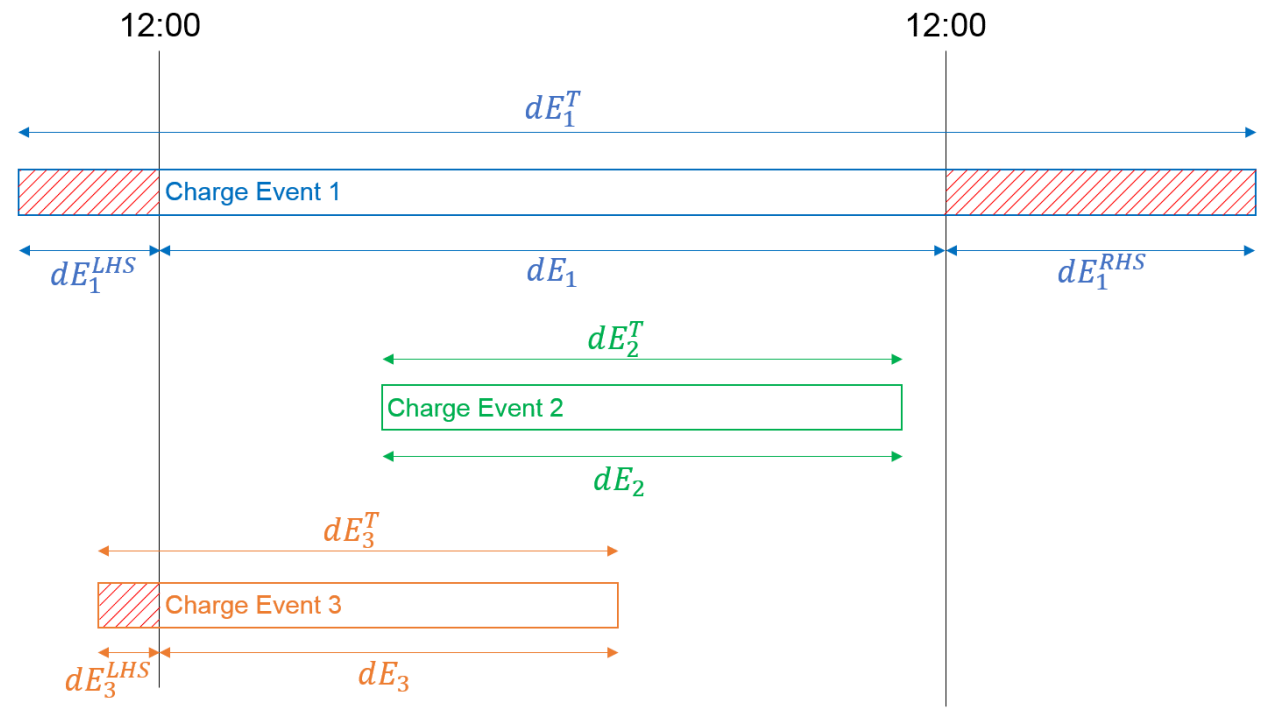

Figure 4: Illustrative example of charging flexibility window concept, showing how 7-day charging schedules are trimmed to 1-day charging flexibility windows for optimisation

Figure 4 illustrates how charge events are modified. Upon selection of the 24 hour window within the 7-day long charging schedule, any charge events that are completely outside of the 24 hour window are discarded. Any that overlap the beginning and/or the end of the 24 hour window (e.g. Charge Events 1 and 3 in Figure 4) are trimmed accordingly as per (1), such that only the energy that would ordinarily have been delivered during the 24 hour window - under a 'dumb' charging schedule - is accounted for.

$$
d E_{e}=d E_{e}^{\mathrm{T}}-\left(d E_{e}^{\mathrm{LHS}}+d E_{e}^{\mathrm{RHS}}\right)
$$

where $d E_{e}^{\mathrm{T}}$ is the total energy received by the vehicle during charging event $e, d E_{e}$ is the trimmed energy, $d E_{e}^{\mathrm{LHS}}$ is the energy to be trimmed from the charge event $e$ overlapping the start of the 24 hour window and $d E_{e}^{\mathrm{RHS}}$ is the energy to be trimmed from the charge event $e$ overlapping the end of the 24 hour window. 
The energy that is to be trimmed from these charge events is calculated by consideration of a standard constant current-constant voltage (CC-CV) charging profile of a Lithium-ion battery, as used in [24, 29-34]. The resulting expressions for the calculation of $d E_{e}^{\mathrm{LHS}}$ and $d E_{e}^{\mathrm{RHS}}$ are given in (2). For the derivation of these expressions, the reader is referred to [24].

$$
\begin{aligned}
d E_{e}^{\mathrm{LHS}}= & \frac{\max \left\{0,\left(t_{e}^{\gamma_{e}}-t_{e}^{s}\right)\right\}}{\left(t_{e}^{\gamma_{e}}-t_{e}^{s}\right)} \int_{t_{e}^{s}}^{t_{e}^{\gamma_{e}}} \mathrm{P}_{e}^{\max } d t+ \\
& \frac{\max \left\{0,\left(t_{e}^{s^{\prime}}-t_{e}^{\gamma_{e}}\right)\right\}}{\left(t_{e}^{s^{\prime}}-t_{e}^{\gamma_{e}}\right)} \int_{t_{e}^{\gamma_{e}}}^{t_{e}^{s^{\prime}}} \mathrm{P}_{e}^{\max } e^{-\lambda_{e} t} d t \\
d E_{e}^{\mathrm{RHS}}= & \frac{\max \left\{0,\left(t_{e}^{\gamma_{e}}-t_{e}^{d}\right)\right\}}{\left(t_{e}^{\gamma_{e}}-t_{d}^{s}\right)} \int_{t_{d}^{s}}^{t_{e}^{\gamma_{e}}} \mathrm{P}_{e}^{\max } d t+ \\
& \frac{\max \left\{0,\left(t_{e}^{d^{\prime}}-t_{e}^{\gamma_{e}}\right)\right\}}{\left(t_{e}^{d^{\prime}}-t_{e}^{\gamma_{e}}\right)} \int_{t_{e}^{\gamma_{e}}}^{t_{e}^{\min }} \mathrm{P}_{e}^{\max } e^{-\lambda_{e} t} d t
\end{aligned}
$$

where $t_{e}^{s}$ is the original start time of the charge event $e, t_{e}^{s^{\prime}}$ is the adjusted start time of the charge event $e$ (i.e. the start of the 24 hour window), $t_{e}^{d}$ is the original departure time of charge event $e$ and $t_{e}^{d^{\prime}}$ is the adjusted departure time of the parking event following trip $e$ (i.e. the end of the 24 hour window). $t_{e}^{\gamma_{e}}$ is the time at which the EV's SoC reaches $\gamma_{e}$, the point at which the charging profile transitions from the $\mathrm{CC}$ to the $\mathrm{CV}$ region for charge event $e$-taken in this study to be 0.8 , as shown in Figure 8. $\lambda_{e}$ is the decay constant associated with the $\mathrm{CV}$ region. $t_{e}^{\infty}$ is the time at which the charging power reaches a value close to zero (taken as $1 \%$ of the maximum rated power) and the charger switches off on account of the vehicle's battery being full. $t_{e}^{\min }$ is the minimum of $t_{e}^{d}$ and $t_{e}^{\infty}(3)$.

$$
t_{e}^{\min }=\min \left\{t_{e}^{d}, t_{e}^{\infty}\right\}
$$

\section{Grid Carbon Intensity and Wind Curtailment Modelling}

\subsection{Grid Carbon Intensity}

Half-hourly carbon intensity data for the GB grid was obtained from National Grid [21]. Table 4 shows the assumed carbon intensity of each generation type, which is used by National Grid to calculate the carbon intensity based on the generation mix per half-hour settlement period. 
Table 4: Carbon Intensity and generation by fuel type from 1 June 2018 to 31 May 2019; data: $[21,22]$

\begin{tabular}{llll} 
Fuel Type & $\begin{array}{l}\text { Carbon Intensity } \\
\left(\mathbf{g C O}_{\mathbf{2}} / \mathbf{k W h}\right)\end{array}$ & $\begin{array}{l}\text { Generation } \\
(\mathbf{T W h})\end{array}$ & $\begin{array}{l}\text { Generation } \\
\mathbf{( \% )}\end{array}$ \\
\hline Gas - Combined Cycle & 394 & 115.3 & 41.0 \\
Gas - Open Cycle & 651 & 0.01 & 0.0 \\
Wind & 0 & 41.08 & 14.6 \\
Hydro & 0 & 5.3 & 1.9 \\
Coal & 937 & 9.7 & 3.4 \\
Nuclear & 0 & 57.1 & 20.3 \\
Dutch Imports & 474 & 6.7 & 2.4 \\
French Imports & 53 & 12.8 & 4.6 \\
Irish Imports & 458 & 1.8 & 0.7 \\
Solar & 0 & 11.5 & 4.1 \\
Biomass & 120 & 17.1 & 6.1 \\
Other & 300 & 2.8 & 1.0 \\
\hline Total & - & 281 & -
\end{tabular}

Based on the data in Table 4, the average GB grid carbon intensity for 1 June 2018 to 31 May 2019 is estimated at $221 \mathrm{gCO}_{2} / \mathrm{kWh}$. This figure continues the significant reduction in carbon intensity from $469 \mathrm{~g} / \mathrm{kWh}$ (combustion only) for the UK in 2013 [8], to under $350 \mathrm{~g} / \mathrm{kWh}$ in 2015 [35]. To meet UK government targets for decarbonisation, these trends must continue to be in line with the Committee on Climate Change (CCC) target of below $200 \mathrm{~g} / \mathrm{kWh}$ for 2020 to below $100 \mathrm{~g} / \mathrm{kWh}$ in 2030 [36].

In this study, a Monte Carlo-based method is used to conduct the analysis for 100 trials, i.e. 100 simulated fleets of EVs, each based on a run of the method shown in Algorithm 1, with 100 sets of resulting charging schedules. Each trial, in which a 24 hour period of the EVs' charging schedules are optimised for minimal carbon intensity, is conducted over a matching 24 hour period of carbon intensity data. The grid carbon intensity of the 10024 hour periods as used in this study were selected randomly from the period 1 June 2018 to 31 May 2019 (Figure 5). 


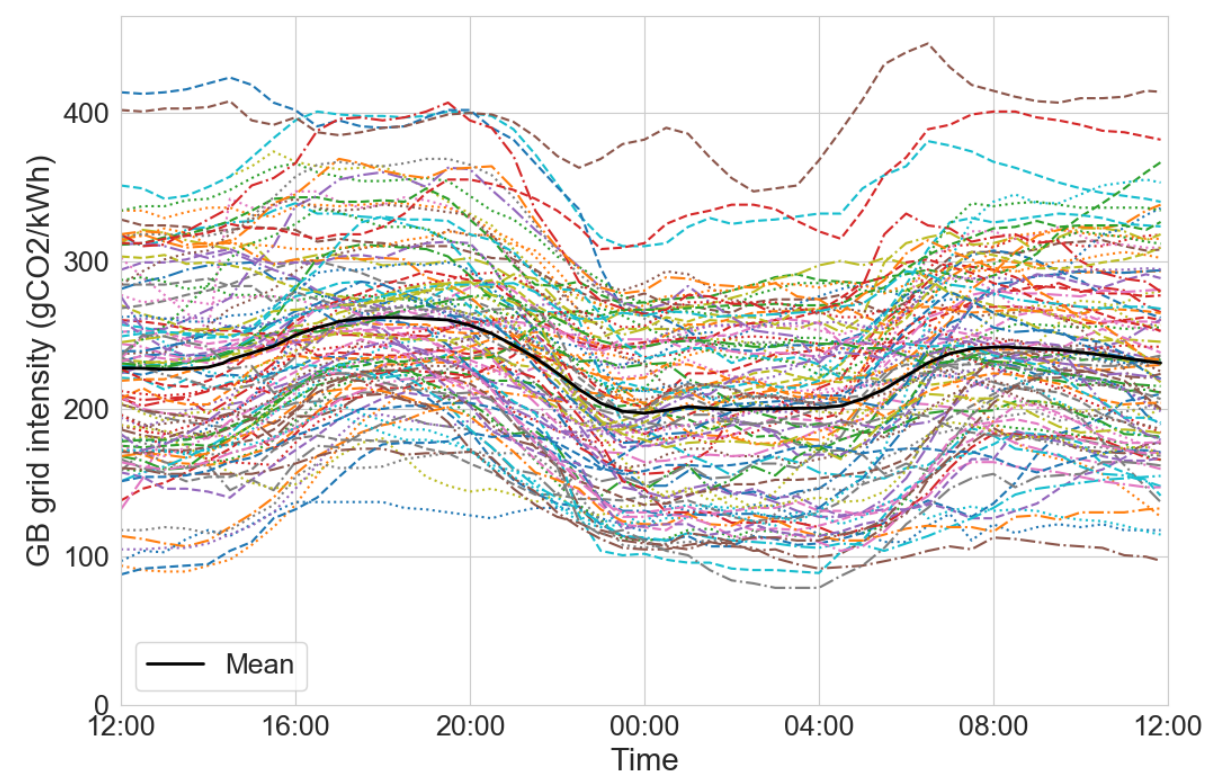

Figure 5: Half-hourly GB grid carbon intensity $\left(\mathrm{gCO}_{2} / \mathrm{kWh}\right)$ for 100 randomly selected weekdays in the period 1 June 2018 to 31 May 2019

Figure 5 shows significant variation in the grid carbon intensity, ranging from $79 \mathrm{gCO}_{2} / \mathrm{kWh}$ at 04:00 on 23 August 2018 to $447 \mathrm{gCO}_{2} / \mathrm{kWh}$ at 07:00 on 23 January 2019. The mean carbon intensity value at each settlement period is shown to be lower in the night-time (22:00-05:00) than in the day. This is an important result, as EV charging is generally more likely to be done overnight as people are parked at home [37].

\subsection{Wind Curtailment}

Whitelee wind farm is a 215-turbine, $539 \mathrm{MW}$ onshore wind farm near Eaglesham, approximately $15 \mathrm{~km}$ to the south of Glasgow. Wind generation in Scotland is curtailed if exports from Scotland exceed the capacity of the B6 boundary - the transmission corridor between Scotland (which usually runs a generation surplus) and England (which usually runs a deficit). During these times, the wind farm's output is curtailed at an average cost of $£ 70 / \mathrm{MWh}$ (based on the average bid price from [22]). Whitelee represented $11.5 \%$ of total Scottish wind farm curtailment from 1 June 2018 to 31 May 2019. 
The wind farm and test network are in close proximity; electrically, they are connected by 275 and $132 \mathrm{kV}$ transmission lines. It is assumed that these have sufficient capacity headroom to allow increased demand from Glasgow (as a result of EV charging) to be balanced by curtailed wind energy from Whitelee (Figure 6, adapted from [38]). Therefore, for any period in the 100 days represented in Figure 5 in which there was also curtailment at Whitelee, the grid carbon intensity for that period was set to $0 \mathrm{gCO}_{2} / \mathrm{kWh}$ - in accordance with the methodology used in [21].

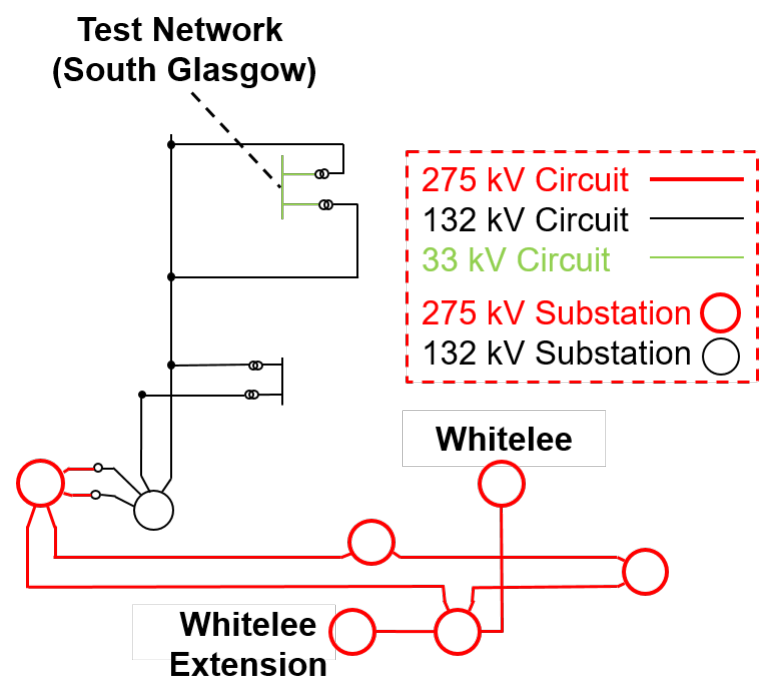

Figure 6: Network diagram from Whitelee wind farm to the test network in the south side of Glasgow, adapted from [38]. Note: Sections of the electrical line diagram have been removed to focus on the connection between Whitelee and the test network location.

Half-hourly curtailment data for the Whitelee wind farm was obtained from the Elexon Balancing Mechanism Reports [22]. Out of 365 days from 1 June 2018 to 31 May 2019, 112 (31\%) saw some curtailment. Figure 7 shows the total curtailment by half-hour settlement period (left) and a histogram of daily curtailment volumes (right) for Whitelee wind farm during that period. 

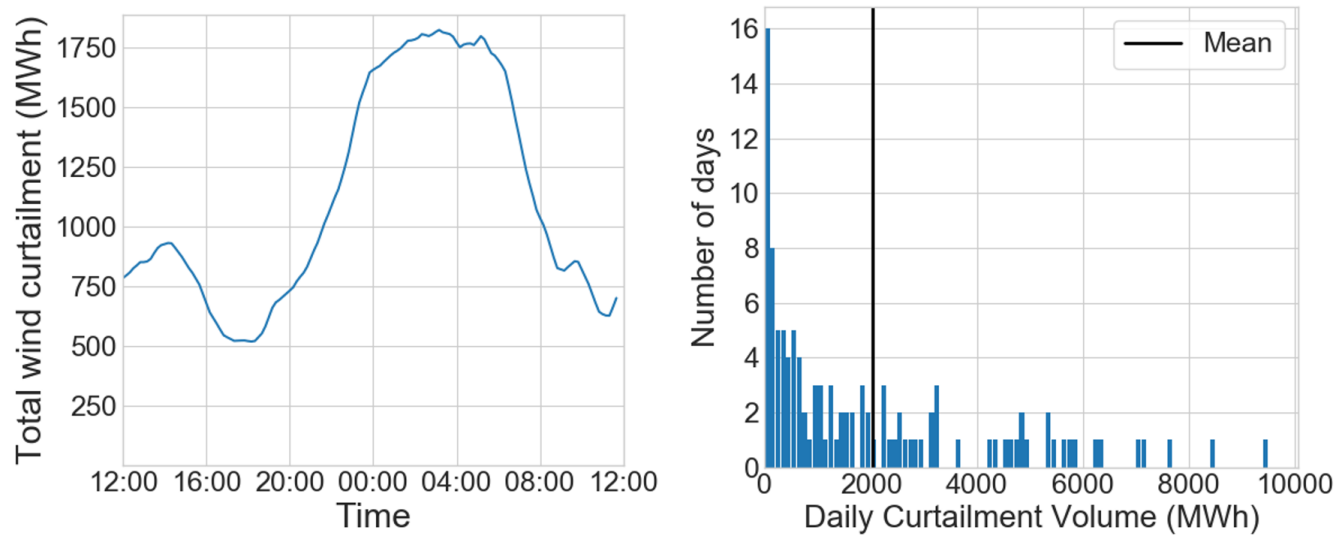

Figure 7: Total wind curtailment volumes by half-hour settlement period (left) and histogram of daily wind curtailment volumes (right) of Whitelee wind farm for 112 days where generation was curtailed, 1 June 2018 to 31 May 2019 (bin width = $100 \mathrm{MWh}$ )

Figure 7 shows that more generation was curtailed at night than in the afternoon and evening, likely due to the sum of domestic and industrial demand being higher in the afternoon/evening than at night. As was the case for carbon intensity, this is an important result as EV charging is generally more likely to be done overnight. Figure 7 also shows that the mean daily curtailment on the 112 days in the year that saw some curtailment was 2030 MWh. The total curtailment of Whitelee wind farm through the year was $227,841 \mathrm{MWh}$ which, at Whitelee's average bid price of $£ 70 / \mathrm{MWh}$, gives a potential value of absorbing this curtailment through EV charging of up to $£ 15.9 \mathrm{~m}^{2}$.

\section{Optimal EV Charging}

In this section, an optimisation model is presented that aims at providing an optimal schedule for EV charging - i.e. that which maximises charging at times of minimum $\mathrm{CO}_{2}$ intensity - whilst respecting network constraints and meeting required energy demand of EVs within their flexibility windows (section 3.4).

\footnotetext{
${ }^{2}$ The total cost of the B6 constraint would be the sum of the cost of accepted bids to reduce output and offers to replace it on the other side of the boundary. Therefore, this value is likely to be an under-estimate of the true value of absorbing this curtailment as it does not include the cost of accepted offers.
} 


\subsection{Power Flow}

The power balance equation is given as (4), $\forall b \in \mathcal{B}, \tau \in \mathcal{T}$ :

$$
\sum_{g \in \mathcal{G}} p_{g, \tau}^{\mathrm{G}}=\sum_{e \in \mathcal{E}} p_{e, \tau}^{\mathrm{E}}+\sum_{d \in \mathcal{D}} p_{d, \tau}^{\mathrm{D}}+\sum_{l \in \mathcal{L}} p_{l, \tau}^{\mathrm{L}}
$$

where $\mathcal{B}$ is the set of busbars in the network, $\mathcal{T}$ is the time horizon (the set of 10 minute timesteps indexed by $\tau$ ), $\mathcal{E}$ is the set of charge events across all EVs in the fleet, $\mathcal{D}$ is the set of domestic demands (i.e. one per household) and $\mathcal{L}$ is the set of lines in the network. $p_{g, \tau}^{\mathrm{G}}$ is the active power contribution from the grid supply point $g$ in the time period $[\tau, \tau+1], p_{e, \tau}^{\mathrm{E}}$ is the active power drawn by an $\mathrm{EV}$ in charge event $e$ to charge its battery in the time period $[\tau, \tau+1], p_{d, \tau}^{\mathrm{D}}$ is the active power drawn by domestic demand $d$ in the time period $[\tau, \tau+1]$ and $p_{l, \tau}^{\mathrm{L}}$ is the active power flow on line $l$ in the time period $[\tau, \tau+1]$.

The power flow equations are given as $(5 \mathrm{a}-5 \mathrm{~b}), \forall l \in \mathcal{L}, \tau \in \mathcal{T}$ :

$$
\begin{gathered}
p_{l, \tau}^{\mathrm{L}}=-\mathrm{B}_{l}\left(\delta_{b, \tau}-\delta_{b^{\prime}, \tau}\right) \\
-\mathrm{S}_{l}^{\max } \leq p_{l, \tau}^{\mathrm{L}} \leq \mathrm{S}_{l}^{\max }
\end{gathered}
$$

where $\mathrm{B}_{l}$ and $\mathrm{S}_{l}^{\max }$ are the susceptance and rating respectively of line $l$, and $\delta_{b, \tau}$ and $\delta_{b^{\prime}, \tau}$ are the voltage angles at $b$ and $b^{\prime}$, denoting the busbars at either end of line $l$, in the time period $[\tau, \tau+1]$.

\subsection{EV Charging Model}

The energy storage content of an EV $E_{e, \tau}$ during charge event $e$ at timestep $\tau$ is related to that in the previous timestep and the energy gained in the time period $\Delta \tau=[\tau, \tau+1]$ (10 minutes) by (6).

$$
E_{e, \tau}=p_{e, \tau}^{\mathrm{E}} \Delta \tau+E_{e, \tau-1}
$$

The power drawn by an EV is constrained by a CC-CV charging profile (Figure 8) typical of lithium ion batteries [24, 29-34], in which the maximum charging power is equal to the rated power $\mathrm{P}_{e}^{\max }$ for a battery $\mathrm{SoC}$ up to $\gamma_{e}$, after which it linearly decreases to zero at an SoC of 1 . In this work, $\gamma_{e}$ is set to 0.8 in accordance with a real lithium ion battery charging profile from an ABB charger as presented in [31]. The charging power constraint is stated formally in (7), $\forall \tau \in \mathcal{T}$ 


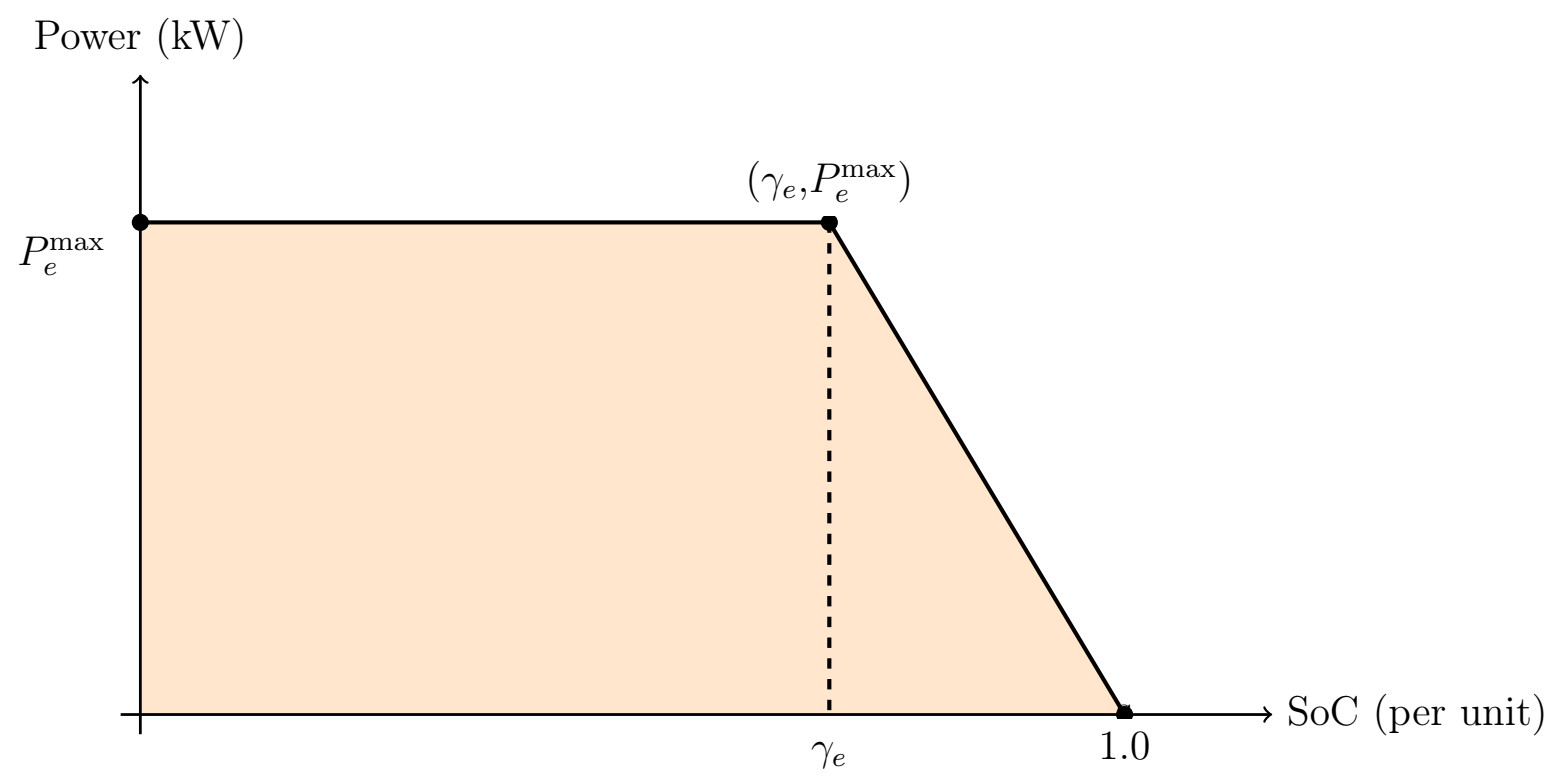

Figure 8: EV charging power constraint as a function of battery SoC

$$
p_{e, \tau}^{\mathrm{E}} \leq \begin{cases}\mathrm{P}_{e}^{\max }, & S o C_{e, \tau} \leq \gamma_{e} \\ \left(\frac{1-S o C_{e, \tau}}{1-\gamma_{e}}\right) \mathrm{P}_{e}^{\max }, & S o C_{e, \tau}>\gamma_{e}\end{cases}
$$

511 where $S o C_{e, \tau}$ is the state of charge of an EV $e$ at timestep $\tau$, calculated as 512 in (8).

$$
S o C_{e, \tau}=\frac{E_{e, \tau}}{\mathrm{E}_{e}^{\max }}
$$

513

514

515

516

517

518

where $\mathrm{E}_{e}^{\max }$ is the EV's battery capacity in charge event $e$.

\subsection{Objective Function}

The goal of the optimisation is to minimise the objective function (9): the sum of the cost of $\mathrm{CO}_{2}$ emissions plus the sum of the cost of not meeting any demand, both domestic and from EV charging. Although the values of lost domestic load and lost transport energy are likely to be different, in this 
work the values of lost load $\mathrm{V}^{\mathrm{D}}$ and $\mathrm{V}^{\mathrm{E}}$ are both taken as $£ 17,000 / \mathrm{MWh}^{3}$ in accordance with the value published by London Economics for the Department of Energy \& Climate Change and Ofgem [39]. The cost of emissions is given by the total emissions in $\mathrm{kg}$ multiplied by a cost per $\mathrm{kg} \Gamma$ - in this work, the UK carbon floor price $(2018-2021)$ of $£ 18 /$ tonne $(£ 0.018 / \mathrm{kg})$ [40] is used.

$$
\begin{array}{r}
\min \sum_{\tau \in \mathcal{T}}(\underbrace{\sum_{g \in \mathcal{G}} \Gamma c_{g, \tau}^{\mathrm{G}} p_{g, \tau}^{\mathrm{G}}}_{\text {CostofCO } 2^{\text {emissions }}}+\underbrace{\sum_{d \in \mathcal{D}} \mathrm{V}_{d}^{\mathrm{D}}\left(\mathrm{P}_{d, \tau}^{\mathrm{D}}-p_{d, \tau}^{\mathrm{D}}\right)}_{\text {Costofsheddingdomesticload }}+ \\
\underbrace{\sum_{i \in \mathcal{I}} \mathrm{V}_{e}^{\mathrm{E}}\left(\mathrm{P}_{e, \tau}^{\mathrm{E}}-p_{e, \tau}^{\mathrm{E}}\right)}_{\text {CostofsheddingEVdemand }}) \Delta \tau
\end{array}
$$

where $c_{g, \tau}^{\mathrm{G}}$ is the grid carbon intensity of grid supply point $g$ during the time period $[\tau, \tau+1] . \mathrm{P}_{d, \tau}^{\mathrm{D}}$ is the active power demand from domestic demand $d$ during the time period $[\tau, \tau+1] ; \mathrm{P}_{e, \tau}^{\mathrm{E}}$ is the active power demand from $\mathrm{EV}$ charging event $e$ during the time period $[\tau, \tau+1]$.

The objective function in (9) is minimised subject to the constraints in (4-8). The problem is solved using the CPLEX solver using OATS [41] optimisation software.

\subsection{Justification of Linearised Optimal Power Flow Formulation}

It is generally acknowledged that a full AC power flow formulation is required to reliably report results for distribution networks given the significant

\footnotetext{
${ }^{3}$ In reality, it would be reasonable to expect that these values would be quite different, due to the variation in consumers' willingness to pay for domestic electricity (which would vary depending on which appliance was being used, when it was being used and, of course, by whom) and transport, which would also be expected to vary significantly in time depending on when any period of lost load would occur relative to tasks that would be deemed important to the consumer. However, as in this study the network was able to serve all load within thermal limits under the DC power flow assumptions, any relative difference in these values would have zero effect on the results presented.
} 
line impedances and consequential variation in voltage magnitudes and angles [42]. To reduce the computational burden of the Monte Carlo approach used in this study, the linearised approach detailed in sections 5.1-5.3 was applied. To check the suitability of the approach, the resulting controlled EV charging profiles were input as loads to an AC load flow. The minimum endpoint voltage for all endpoint busbars in the network recorded over the 24 hour period modelled for each combination of EV parameters, for both minimal and routine charging schedules, is shown in Figure 9. Across 100 trials, the mean of the minimum voltages for each endpoint is shown by the marker and the $95 \%$ confidence interval is shown by the error bars on each side.
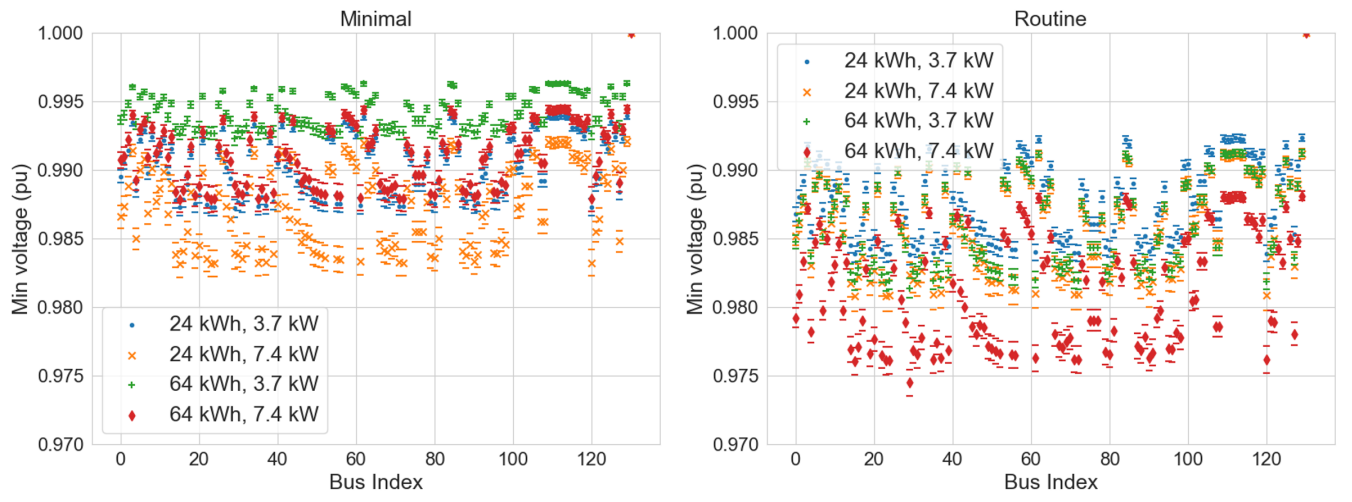

Figure 9: Minimum endpoint voltage resulting from controlled EV charging schedules and domestic loading, all combinations of EV parameters - minimal (left) and routine (right) charging behaviour

Figure 9 shows the variation in voltage stress placed on the network by different EV parameter combinations and charging scheduling models; these patterns are further discussed in section 6.1. It should be noted that no matter the variation, all voltages are within statutory GB limits of $+10 /-$ $6 \%$.

\subsection{Carbon Intensity Minimisation}

The optimisation described in sections 5.1-5.3 is performed for the 100 24hour periods as shown in Figure 5. For each 24-hour period, a different set of generated household demand profiles (Figure 2) and EV charge events (based on the instantiation of EVs and travel diaries in the network as per Algorithm 
1) is used. The resulting seven day charging schedules were trimmed to 'charging flexibility windows' as per the method described in section 3.4. By performing the optimisation, the EVs' charging demand is shifted to times of minimal carbon intensity where their flexibility windows and the constraints in (4-7) allow. The same analysis is carried out for four different combinations of EV battery capacity $(24 \mathrm{kWh}, 64 \mathrm{kWh})$ and charger power $(3.7 \mathrm{~kW}, 7.4$ $\mathrm{kW})$.

Results are presented both with and without the inclusion of curtailment from Whitelee wind farm. For the former, this was represented by the substitution of the grid carbon intensity with $0 \mathrm{gCO}_{2} / \mathrm{kWh}$ for any timestep where curtailment of Whitelee occurred. The volume of wind curtailment was neglected in this analysis because any curtailed volume in the period analysed was three orders of magnitude greater than the peak EV charging demand from the test network.

\subsection{Wind Generation Curtailment Reduction}

A single bus model was used (Figure 10), with a generator to represent the volume of curtailed wind energy from Whitelee (taken from [22]). The volume of curtailed wind is compared for an increasing number of EVs from 10,000 to $1,000,000$, for both the minimal and routine charging schedule models. LV network constraints are not considered in this part of the work due to the computational burden involved - it is recognised that this could limit the flexibility available from EVs and further work into this area is highlighted in section 7. Managing distribution network constraints, and coordinating access to flexible assets between distribution and transmission level markets is a subject of ongoing research [43-45], and is out of the scope of this work.

There are currently over 2.4 million private cars in Scotland [46] and, based on the Scottish Government's target for all sales of new cars and vans to be zero emission by 2032 [47], it is reasonable to expect that there could be at least a million battery EVs within the Scottish 'Central Belt', where approximately $65 \%$ of the population live (i.e. behind the B6 boundary constraints which result in curtailment at Whitelee). 


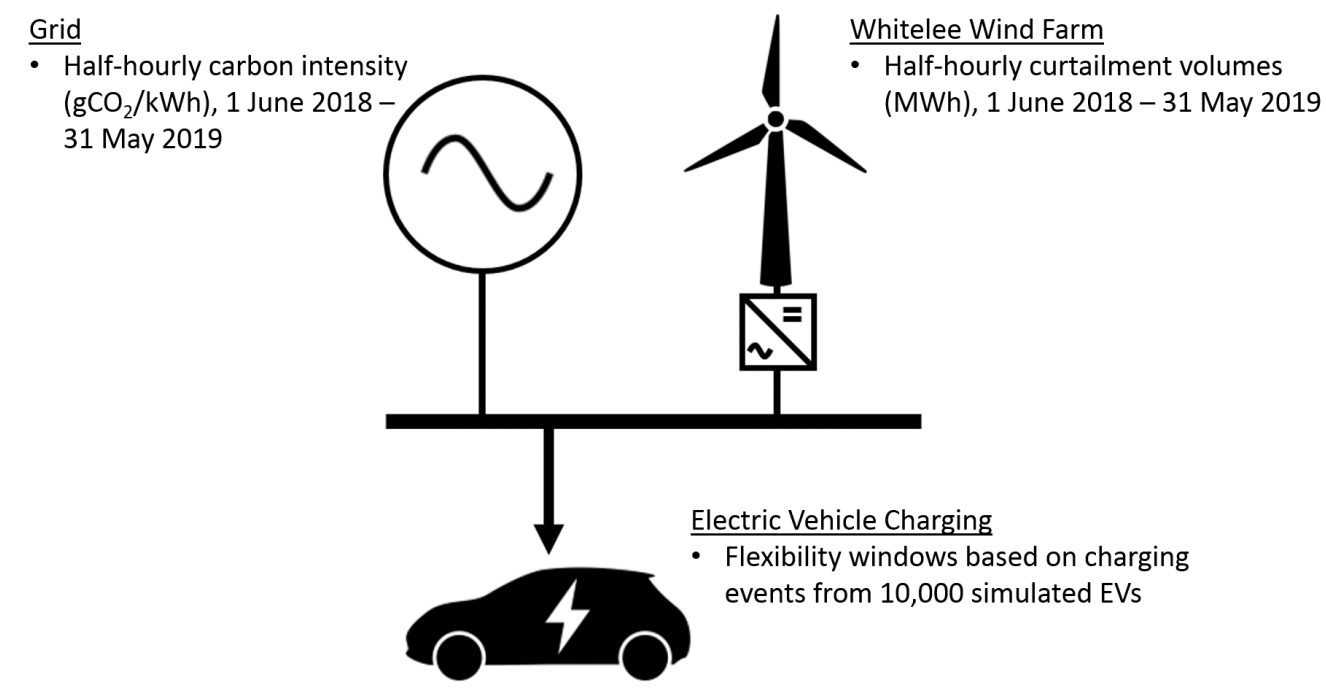

Figure 10: Schematic showing single bus model used to study potential of EV charging to utilise excess wind generation

Simulating up to 1,000,000 individual EVs was not possible as this would exceed the amount of travel data on record. 10,000 simulated EVs were scaled up to $50,000,100,000,250,000,500,000,750,000$ and 1,000,000 EVs by multiplying the battery capacity $\mathrm{E}_{e}^{\max }$, charger power $\mathrm{P}_{e}^{\max }$, initial energy storage content $\mathrm{E}_{e}^{\text {start }}$ and final energy storage content $\mathrm{E}_{e}^{\text {end }}$ of each $\mathrm{EV}$ accordingly. This approach of aggregating EVs to form large flexible demands has been demonstrated before - as previously discussed in section 1.2 - in [15] and [16].

A spread of EV battery capacities is analysed, with each vehicle being assigned a battery capacity randomly out of a set of capacities found on the EV market: 24, 30, 40, 60 and $75 \mathrm{kWh}$. All EVs were assumed to have $7.4 \mathrm{~kW}$ charging capability, to reflect the trend towards higher power home chargers ${ }^{4}$.

The linearised problem formulation in (4-8) was used to minimise carbon

\footnotetext{
${ }^{4}$ in the UK, there is generally no difference in price between 'slow' and 'fast' home chargers - e.g. the WallPod EV charger retails at £320 in the UK for either 3.7 or $7.4 \mathrm{~kW}$ configuration [48] - thus it is likely that $7.4 \mathrm{~kW}$ chargers will soon become the norm.
} 
intensity as in the carbon intensity minimisation study. As shown in Figure 10 , a generator was used to represent the curtailment at Whitelee wind farm whose power output was constrained as per (10).

$$
p_{w, \tau}^{\mathrm{G}} \leq \mathrm{P}_{w, \tau}^{\mathrm{UB}}
$$

where $\mathrm{P}_{w, \tau}^{\mathrm{UB}}$ represents the maximum power output from the wind generator $w$ in time period $\tau$, equal to the average curtailed wind power per timestep at Whitelee: therefore, in periods with no wind curtailment, $\mathrm{P}_{w, \tau}^{\mathrm{UB}}$ is zero.

The wind generator was modelled as having $0 \mathrm{~g} / \mathrm{kWh}$ carbon intensity and the grid was modelled as having the national carbon intensity. The 112 days on which curtailment occurred at Whitelee were modelled with increasing EV numbers to establish how effectively the flexibility from EVs could be used to reduce wind curtailment based on real curtailment data.

\section{Results}

Results are presented for the minimisation of the $\mathrm{CO}_{2}$ emissions associated with EV charging (section 6.1) and for the minimisation of curtailment at Whitelee wind farm (section 6.2).

\subsection{Controlling Electric Vehicle Charging to Minimise Carbon Intensity 6.1.1. Charging demand profiles}

Figures 11 and 12 show the uncontrolled charging profiles for the 100 days simulated for the minimal and routine charging schedules respectively, with a solid black line showing the mean charging demand in all cases. 

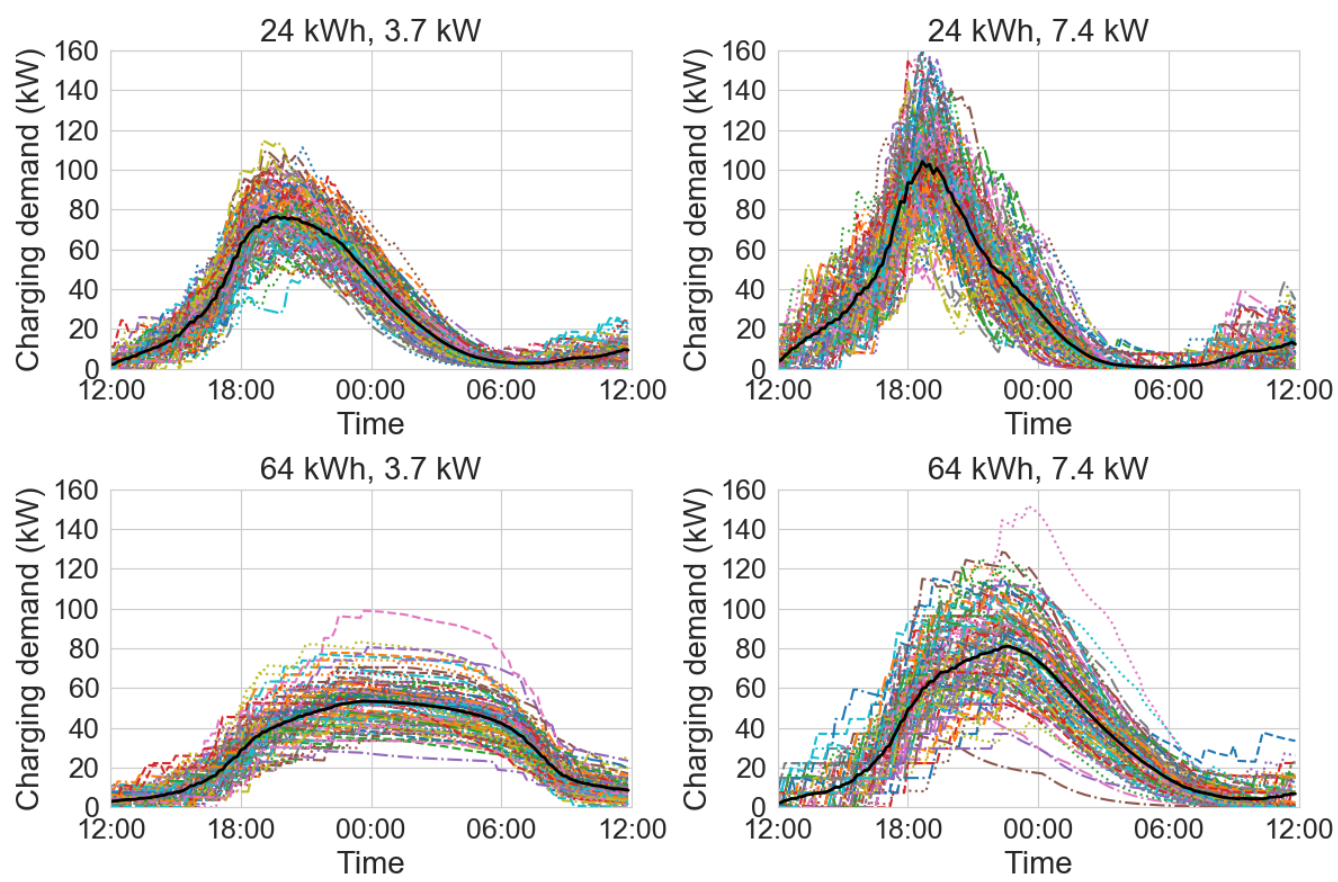

Figure 11: Uncontrolled charging demand profiles for all battery size/charger power combinations - minimal charging behaviour 

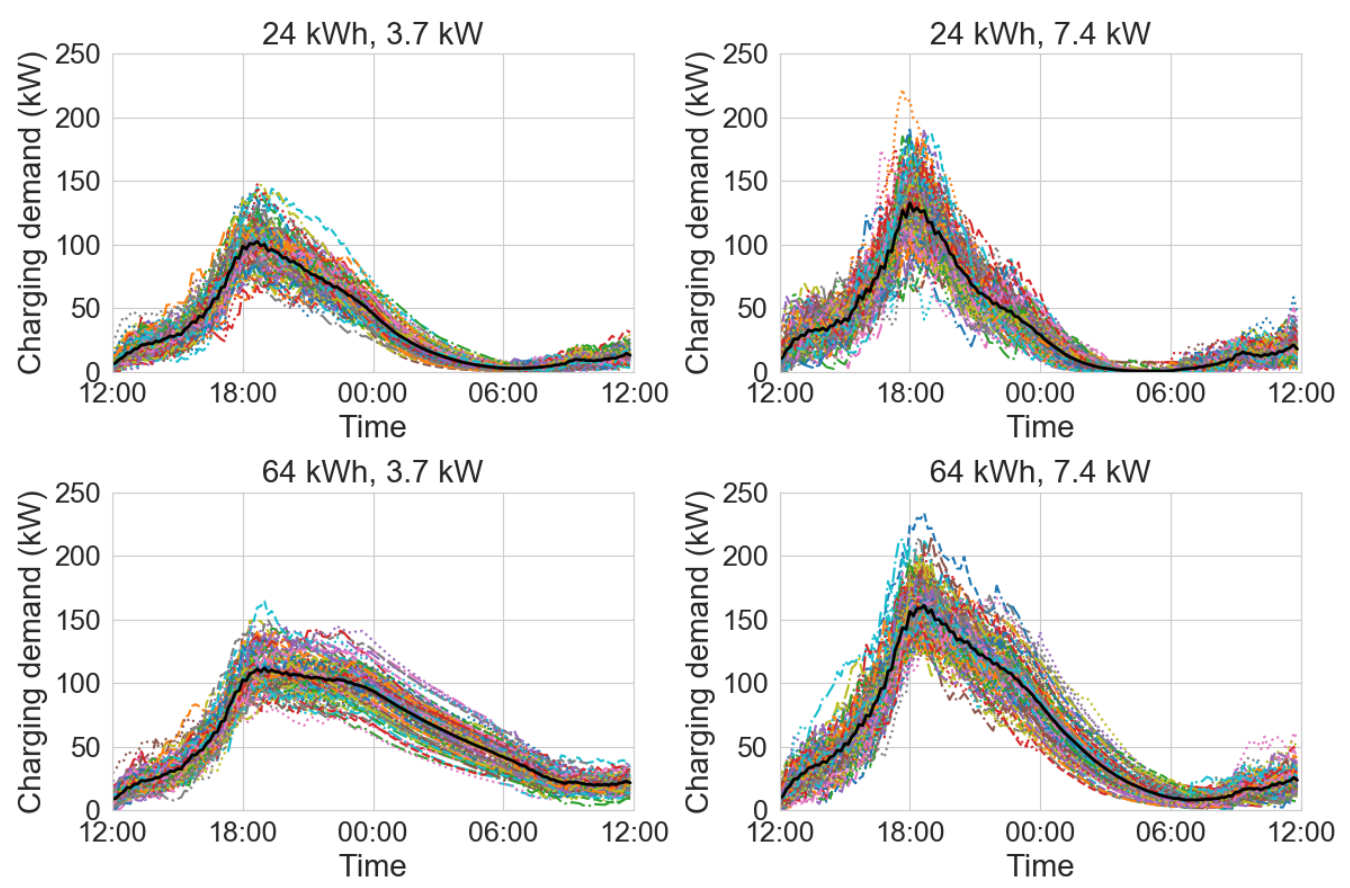

Figure 12: Uncontrolled charging demand profiles for all battery size/charger power combinations - routine charging behaviour

The effect of EV parameters on uncontrolled EV charging demand is shown in Figures 11 and 12. When drivers are trying to minimise their charging frequency (as in Figure 11), an increase in battery size leads to a reduction in the peak demand, and a shift of the peak to a later point in the evening. Increasing the charger power leads to a sooner, sharper peak with a greater magnitude. If drivers routinely plug their EVs in irrespective of their $\mathrm{SoC}$ (as in Figure 12), several interesting effects can be observed. The variation in charging profiles day to day becomes smaller, and the effect of battery size is reduced. The longer 'tail' of the charging profile in the larger battery sizes compared to the smaller ones is due to a larger energy storage, enabling the possibility of a longer charging duration. Increasing charging power is still shown to bring the peak charging demand forward and increase its magnitude.

Figures 13 and 14 show the controlled charging profiles for the 100 days, after having been scheduled as per the method presented in section 5 , for the minimal and routine charging schedule models respectively. 

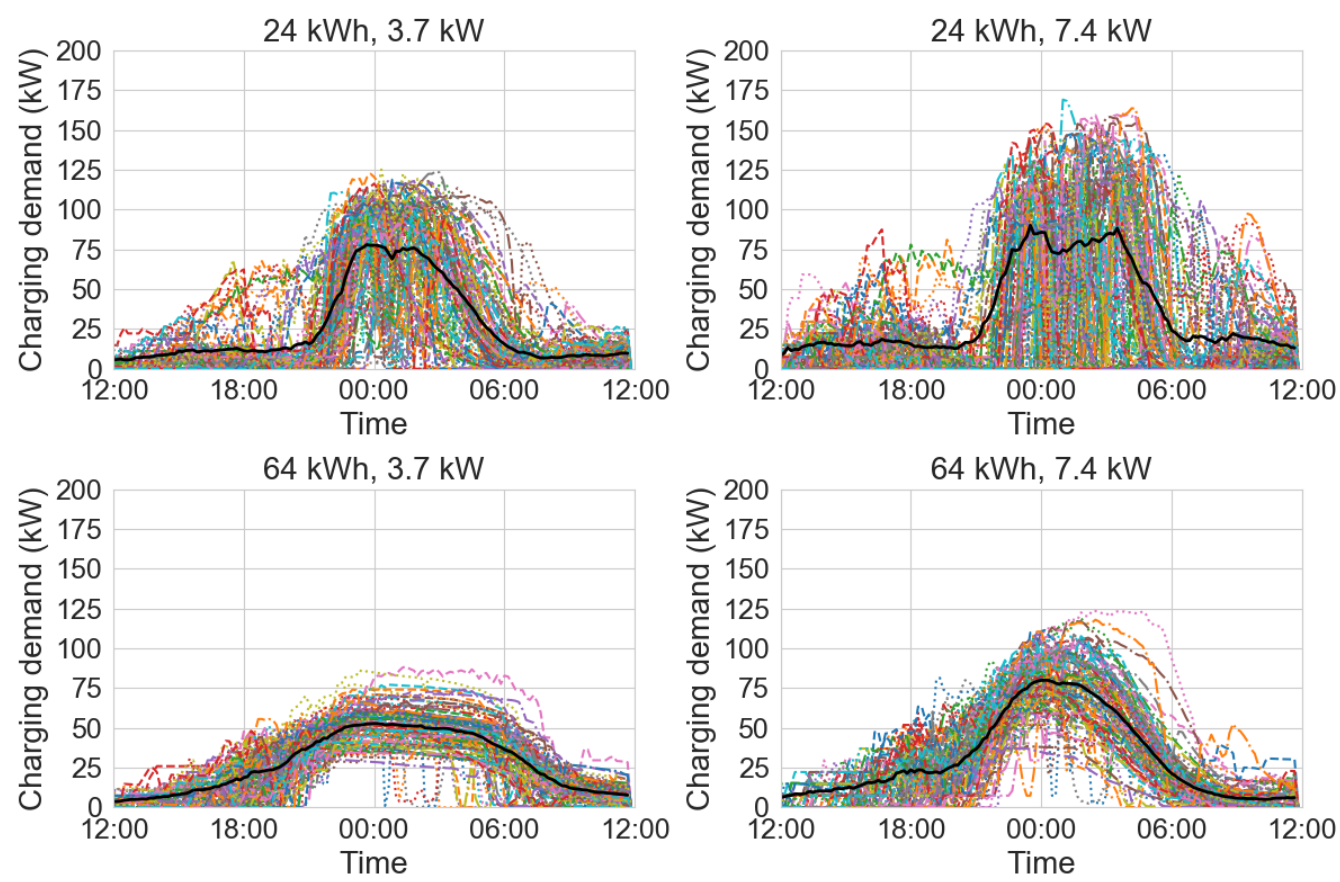

Figure 13: Controlled charging demand profiles (minimisation of carbon intensity) for all battery size/charger power combinations - minimal charging behaviour 

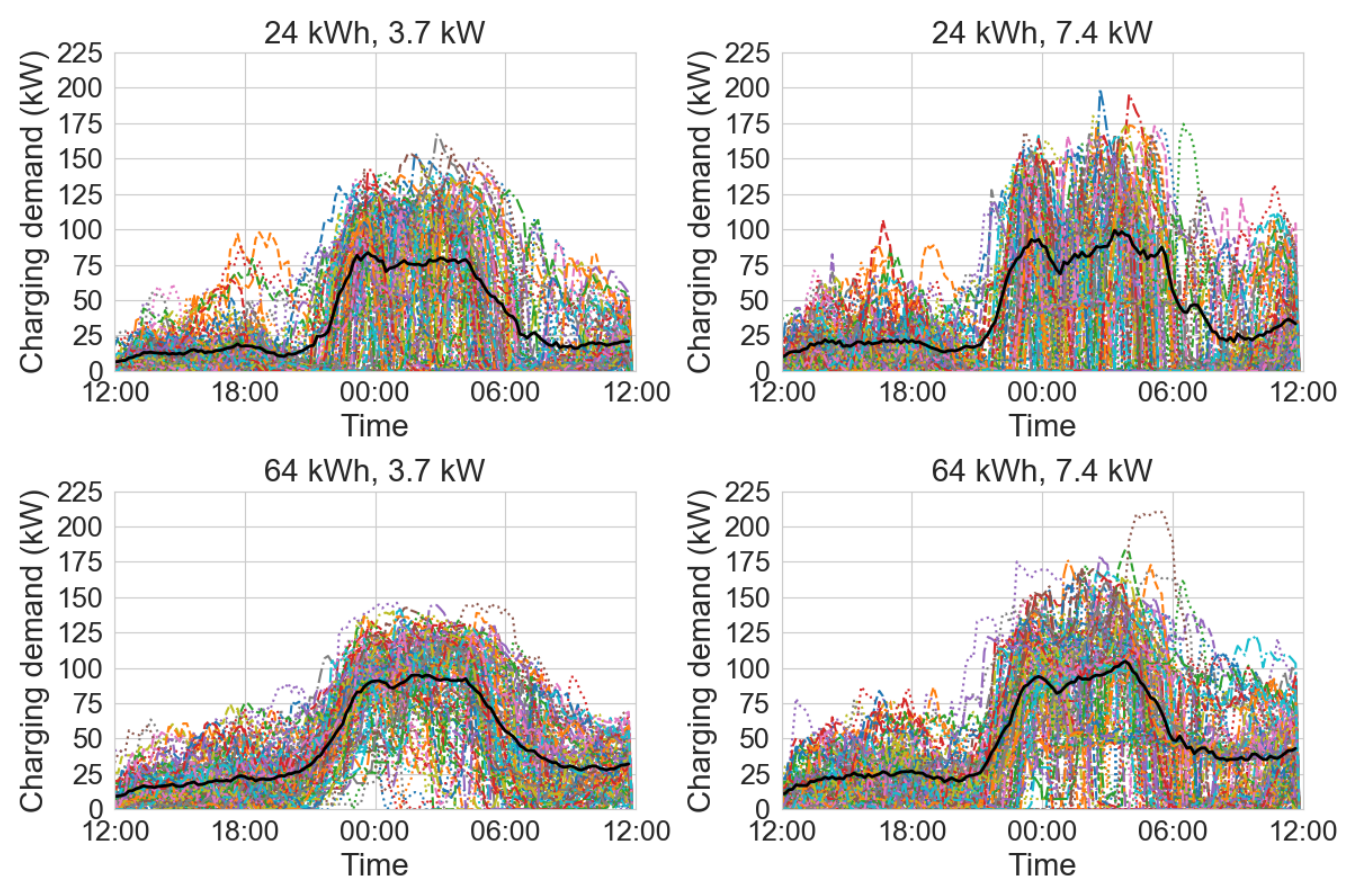

Figure 14: Controlled charging demand profiles (minimisation of carbon intensity) for all battery size/charger power combinations - routine charging behaviour

A great variation in controlled charging demand is shown in Figures 13 and 14 , which is a direct result of the significant variation in carbon intensity (Figure 5). It is shown in the black solid lines representing the mean charging profile that the bulk of charging demand was usually delayed to the middle of the night where carbon intensity is lowest. In the minimal charging schedule case, there is shown to be significantly less variation in the controlled charging load for the larger battery size, especially with the slow charging rate. This is suggested to be due to a lower flexibility with these charge events; as these drivers tend to plug in on fewer occasions, their energy demand from any given charge event is greater; furthermore, if the charging power is lower, there is less that can be done to shift this charging demand in time. If drivers plug in routinely, the mean controlled charging profiles are more similar to one another. This is suggested to be due to an increased flexibility of the charging events for EVs with bigger batteries, due to an increase in their charging frequency and therefore a reduction in the required energy from a given charge event. 


\subsubsection{Reduction in Carbon Intensity of EV Charging}

Figures 15 and 16 show boxplots of the carbon intensity associated with all charge events on all 100 days in the simulation for uncontrolled charging then controlled charging, with and without consideration of curtailment of Whitelee wind farm, for the minimal and routine charging schedule cases respectively.
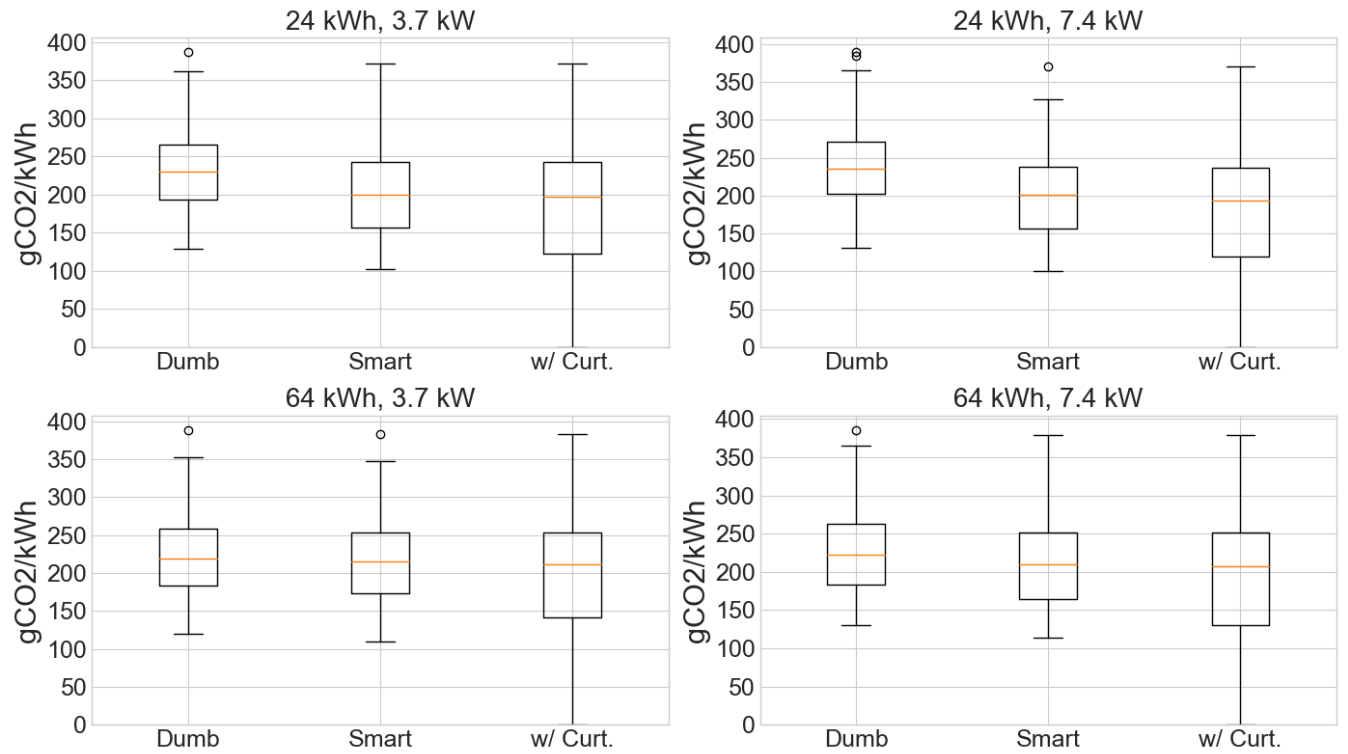

Figure 15: Reduction in carbon intensity from controlled charging, with and without the inclusion of curtailment from Whitelee wind farm, for all battery size/charger power combinations - minimal charging behaviour 

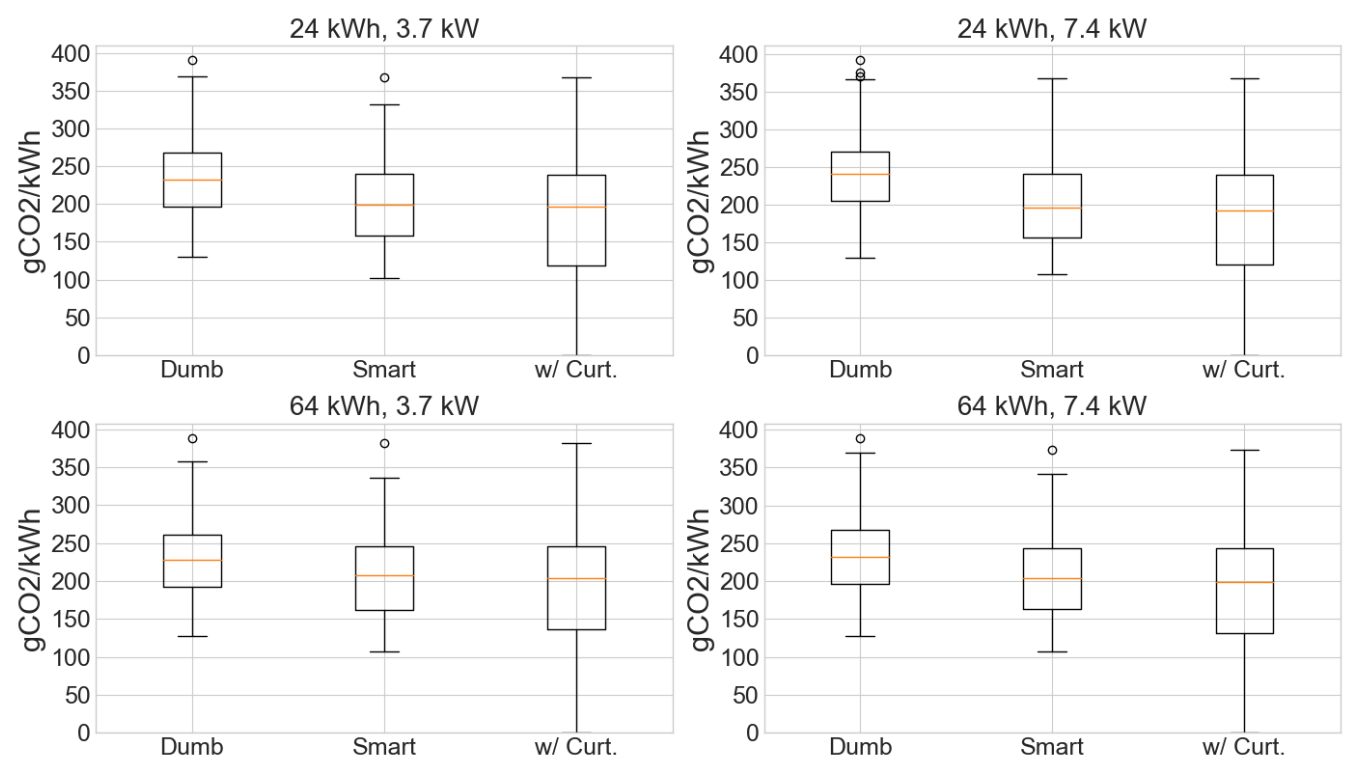

Figure 16: Reduction in carbon intensity from controlled charging, with and without the inclusion of curtailment from Whitelee wind farm, for all battery size/charger power combinations - routine charging behaviour

Figures 15 and 16 show a steady reduction in the carbon emissions associated with EV charging. As previously discussed, the charging load of EVs with larger batteries under the minimal charging model is less flexible than those under the routine charging model; as a result, it is shown that if $\mathrm{EV}$ drivers with large batteries only plug in when they need to, it is more difficult for controlled charging to reduce the carbon intensity associated with their vehicles' charging.

The reduction in the mean carbon intensity associated with EV charging for all parameter combinations and both charging scheduling models is shown in Tables 5 and 6 . 
Table 5: Summary results: reduction in mean carbon intensity of driving $\left(\mathrm{gCO}_{2} / \mathrm{kWh}\right)$ from smart charging with and without consideration of curtailment of Whitelee wind farm - minimal charging schedules

\begin{tabular}{llll}
\hline \multicolumn{2}{c}{ Mean Carbon Intensity $\left(\mathbf{g C O}_{\mathbf{2}} / \mathbf{k W h}\right)-$ Minimal Charging } \\
\hline Parameters & $\begin{array}{l}\text { Dumb } \\
\text { Charge }\end{array}$ & Smart Charge & $\begin{array}{l}\text { With } \\
\text { ment }\end{array}$ \\
\hline $24 \mathrm{kWh}, 3.7 \mathrm{~kW}$ & 234.0 & $201.7(-13.8 \%)$ & $176.2(-24.7 \%)$ \\
$24 \mathrm{kWh}, 7.4 \mathrm{~kW}$ & 241.5 & $199.7(-17.3 \%)$ & $171.4(-29.0 \%)$ \\
$64 \mathrm{kWh}, 3.7 \mathrm{~kW}$ & 221.8 & $215.0(-3.1 \%)$ & $193.5(-12.8 \%)$ \\
$64 \mathrm{kWh}, 7.4 \mathrm{~kW}$ & 226.4 & $210.5(-7.0 \%)$ & $187.1(-17.4 \%)$ \\
\hline
\end{tabular}

Table 6: Summary results: reduction in mean carbon intensity of driving $\left(\mathrm{gCO}_{2} / \mathrm{kWh}\right)$ from smart charging with and without consideration of curtailment of Whitelee wind farm - routine charging schedules

\begin{tabular}{llll}
\hline \multicolumn{2}{c}{ Mean Carbon Intensity } & $\left(\mathbf{g C O}_{\mathbf{2}} / \mathbf{k W h}\right)-$ Routine Charging \\
\hline Parameters & $\begin{array}{l}\text { Dumb } \\
\text { Charge }\end{array}$ & Smart Charge & With Curtail- \\
& 237.4 & $200.8(-15.4 \%)$ & $172.8(-27.2 \%)$ \\
\hline $24 \mathrm{kWh}, 3.7 \mathrm{~kW}$ & 243.7 & $201.6(-17.3 \%)$ & $172.3(-29.3 \%)$ \\
$24 \mathrm{kWh}, 7.4 \mathrm{~kW}$ & 228.5 & $208.0(-9.0 \%)$ & $182.9(-20.0 \%)$ \\
$64 \mathrm{kWh}, 3.7 \mathrm{~kW}$ & 235.9 & $205.6(-12.8 \%)$ & $179.5(-23.9 \%)$ \\
$64 \mathrm{kWh}, 7.4 \mathrm{~kW}$ & &
\end{tabular}

If EVs are dumb charged (i.e. there is no control of their charging), the $\mathrm{CO}_{2}$ emissions associated with their charging is, on average, in the region 221-243 $\mathrm{gCO}_{2} / \mathrm{kWh}$. For context in vehicle emissions, the average tailpipe emissions of new petrol and diesel cars purchased in Europe in 2019 were $121.5 \mathrm{gCO}_{2} / \mathrm{km}$ and $123.4 \mathrm{gCO}_{2} / \mathrm{km}$ respectively [49]. Given that typical electricity consumption values of EVs on the market from the United States Environmental Protection Agency (EPA) ${ }^{5}$ are in the range from 0.16 $\mathrm{kWh} / \mathrm{km}$ (based on the city consumption of a 2019 Hyundai Kona Electric 64) to $0.23 \mathrm{kWh} / \mathrm{km}$ (based on the highway consumption of a 2018 Tesla Model S 100) [51], this means that associate EV emissions, if charged from

${ }^{5}$ The EPA's Federal Test Procedure is designed to allow direct comparison of emissions and fuel economy between different vehicles for real-world driving conditions based on city and highway driving cycles. These figures tend to be more conservative than European data, which unlike in the US, result from tests carried out by manufacturers themselves. This is likely to have been a key contributing factor in the 'Dieselgate' scandal 2015-present [50]. 
the $2019 \mathrm{~GB}$ generation mix, are in the range 35.4-55.9 $\mathrm{gCO}_{2} / \mathrm{km}$. If $\mathrm{EVs}$ are dumb charged, their carbon intensity is reduced with larger batteries and lower charger power ratings, because this shifts the charging load later into the night (as in Figures 11 and 12) when carbon intensity is typically lower (Figure 5).

Controlling EV charging, such that all EV charge requirements are met and the network is always operated within its thermal limits, can reduce the $\mathrm{CO}_{2}$ emissions associated with charging by up to $17 \%$. Higher charging power enables the greatest reduction, as this enables more of the energy demand to be met in the times of lowest carbon intensity. Increases in battery size are shown to make it more difficult to reduce the carbon intensity of charging, whereas increases in charger power are shown to make it easier. This is because of the effect of these parameters on the flexibility of charge events, as previously discussed. If drivers plug in routinely, the effect of increasing battery size is reduced.

If there is local RES generation to absorb that would otherwise be curtailed, then in this analysis the carbon intensity was set at $0 \mathrm{gCO}_{2} / \mathrm{kWh}$ for these time periods as per the method used in the National Grid carbon intensity calculator [21]. In this case, controlling EV charging to take place in these periods can further reduce the associated emissions of charging, by up to $29 \%$ with respect to the original. Carbon emissions at this level would result in associated emissions of EV driving in the range (using the same energy consumption values as before) 27.6-39.6 $\mathrm{gCO}_{2} / \mathrm{km}$, around a quarter of the corresponding average for petrol and diesel cars.

The carbon intensity of the grid has been modelled as independent of demand. Although the scale of modelling means that the load presented by the EVs' charging is negligible in comparison to GB demand, if such a scheme were implemented on a large (e.g. nationwide) fleet of EVs then their charging would effect grid intensity - if their charging were to come online such that dispatchable thermal plants had to be brought online, then the carbon intensity associated with their charging would be equivalent to the carbon intensity of the dispatchable plant. At present, there are several electricity tariffs on offer in the UK aimed at EV drivers with access to private residential charging, which offer varying electricity prices based on forecasts of RES output and wholesale electricity prices [52-54]. As the penetration of RES continues to increase in line with government targets, an increased variance in grid intensity is likely. By following the regions of lowest grid intensity, the presence of EVs would effectively be incentivising further 
RES generators to come online by providing a greater level of certainty that the energy they generate would be consumed, even if produced outside of a traditional domestic demand peak (such as that shown in Figure 2).

Aside from potentially reducing their own associated carbon emissions, EV charging can potentially use RES generation that would otherwise be curtailed. Results for this part of the study are presented in section 6.2.

\subsection{Controlling Electric Vehicle Charging to Absorb Excess Wind Genera- tion}

Figure 17 shows boxplots of the percentage reduction in curtailment on each of the 112 days with curtailment in the period 1 June 2018 - 31 May 2019 for fleets of EVs of various sizes. Figure 18 shows the total percentage reduction in curtailment over the whole period for the same fleet sizes.
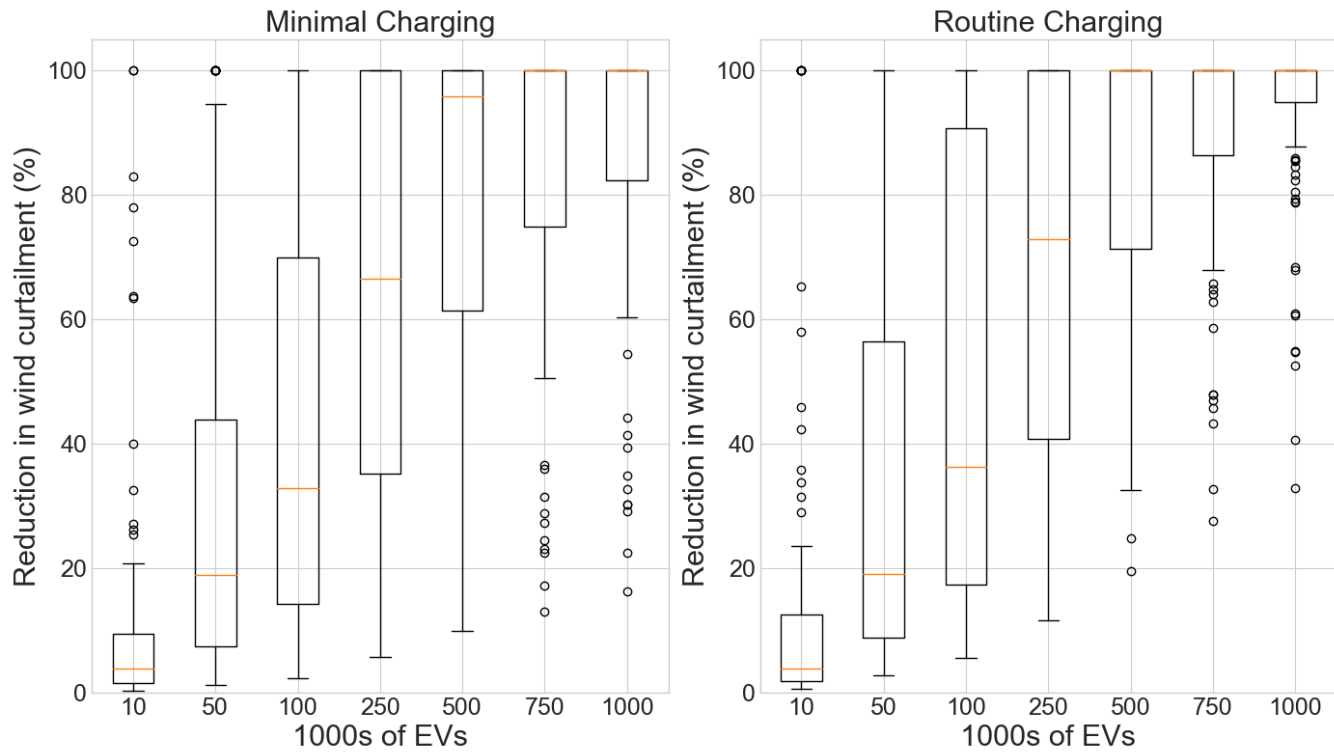

Figure 17: Box plots showing percentage reduction in wind curtailment at Whitelee wind farm on 112 days with curtailment from the optimisation of charging from fleets of EVs of various sizes (1000s) 


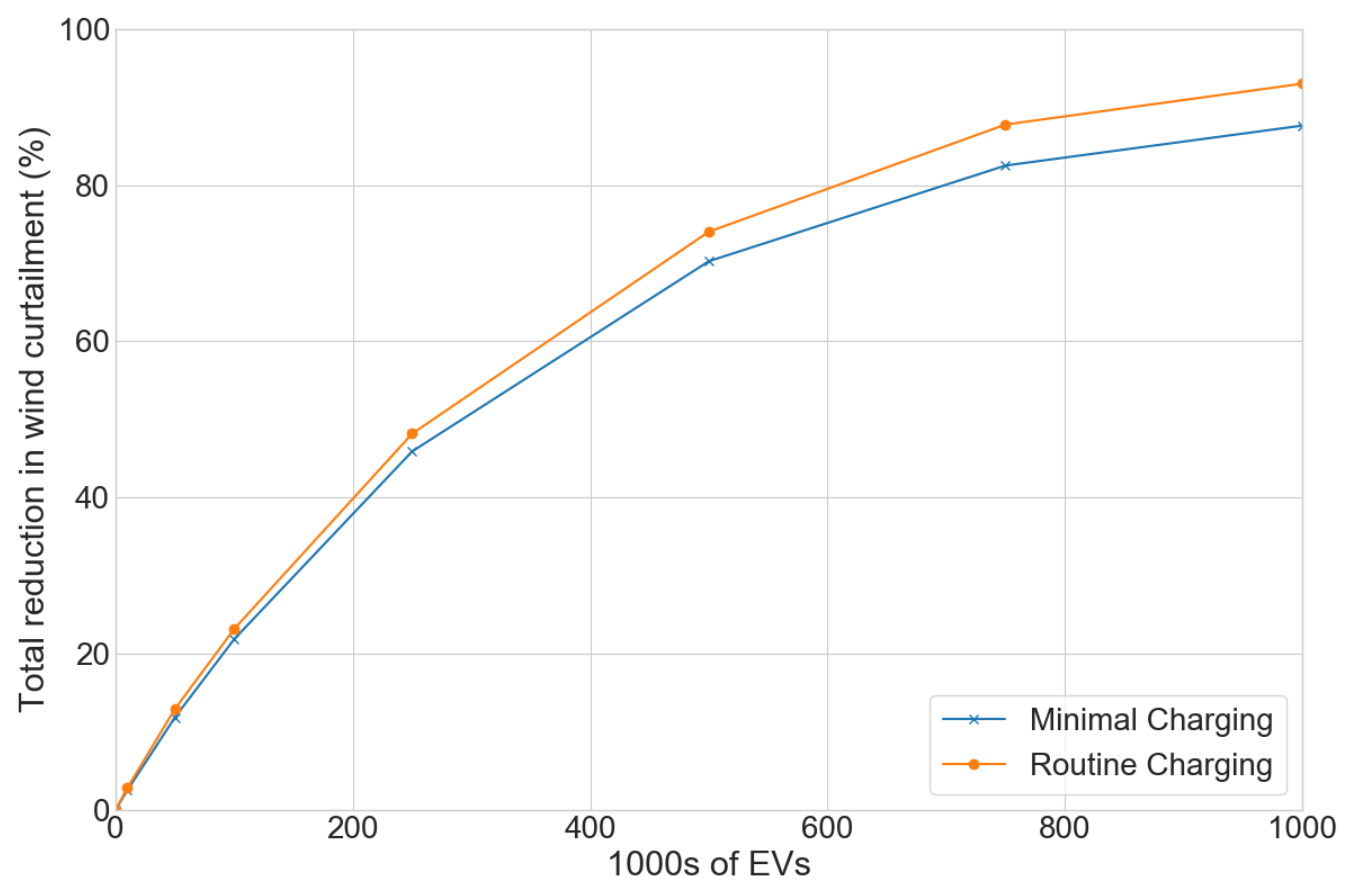

Figure 18: Total reduction in curtailment of generation at Whitelee wind farm over period 1 June 2018 to 31 May 2019 from the optimisation of charging from fleets of EVs of various sizes (1000s)

Figure 17 shows the rate of increase in curtailment reduction as the fleet of EVs increases in size. While the variance is high (due to the variance in the volume of curtailment on each day and the time of day at which this occurs), it is shown that the reduction in curtailment continues to increase with an increasing size of EV fleet. Figure 18 shows that this rate of increase is diminishing; this is due to a subset of days for which the curtailment cannot be reduced to zero even by the charging of 1,000,000 EVs. These are days in which a large volume of curtailment occurs in the middle of the day (when there are fewer EVs plugged in); however, as shown in Figure 7, wind curtailment in the daytime is rarer than in the nighttime.

It is shown in Figure 18 that if drivers charge routinely, then there is more potential for EV charging to be able to reduce curtailment. This effect is most pronounced for large fleets: with a fleet of 1,000,000 EVs, whereas $93.0 \%$ of Whitelee wind farm's total curtailment can be used to charge these EVs if they are charged routinely, $87.6 \%$ of total curtailment can be used 
for the minimal charging case. The reason for these numbers not being vastly different is that the energy for these EVs to carry out their transport requirements remains the same for both cases - though the extra flexibility resulting from routine charging can be better utilised to reduce curtailment at the wind farm. Given that the absorption of this curtailment potentially has significant value, it could be expected that drivers could be incentivised to plug in routinely when arriving home so as to maximise any revenue that may be made from the absorption of curtailment.

\subsection{Discussion - EV Flexibility in the Balancing Mechanism}

A potential market mechanism to reward EV flexibility for reducing wind curtailment is the GB balancing mechanism (BM). Aggregated EV flexibility could be accessed by National Grid ESO in the BM to manage transmission system constraints, offering an alternative to wind curtailment (i.e. rather than paying wind generators to turn down their output, the ESO could pay EV charging aggregators to turn up their demand). However, access to the BM is currently limited for smaller participants such as EVs - this is due to the economics of scale favouring a smaller number of larger units, the requirement for any participant to be a fully licensed supplier (unless granted a derogation by the regulator) and the ESO favouring larger units in the BM at short timescales [55].

However, the introduction of the 'virtual lead party' under the GB implementation of project TERRE will allow smaller aggregators (with a minimum aggregated BM unit size of $1 \mathrm{MW}$ ) to participate in the BM without the need to be fully licensed suppliers $[55,56]$. Furthermore, the ESO has introduced a distributed resource desk, which has resulted in increased participation of industrial and commercial aggregators in the BM [57]. Coupled with the projected growth in EV penetration, this reduction in the barriers to access the BM is likely to contribute positively to the business case of aggregation of EV charging for the provision of grid services.

\section{Conclusion and Further Work}

This paper has presented an investigation into the potential of controlling EV charging to i) reduce the carbon emissions associated with their charging and ii) to provide demand when there is excess renewable electricity generation in the system (that ordinarily has to be curtailed). 
The numerical results presented in this paper represent important quantitative research to network owners, system operators, grid service providers, would-be EV consumers and vehicle manufacturers as it highlights the perceived 'value' of the flexibility of EV charging.

If EV charging were able to follow the times of low carbon intensity and take advantage of RES curtailment, then the emissions associated with their charging was shown to be in the region $27-40 \mathrm{gCO}_{2} / \mathrm{km}$; a $30 \%$ reduction on the 'dumb charging' carbon intensity of 35-56 $\mathrm{gCO}_{2} / \mathrm{km}$. Although this offers an improvement of up to a factor 5 relative to average new petrol and diesel cars, it remains considerably higher than the carbon emissions associated with electrified public transport or other low carbon transport options (e.g. carpooling and cycling/use of e-bikes) [58].

It is shown that there is significant potential to absorb excess RES generation from the flexibility of EV charging: the results shown in section 6.2 imply that a fleet of $500,000 \mathrm{EVs}$, which would equate to an EV penetration of approximately $20 \%$ based on Scotland's total car fleet of 2.4 million, could absorb approximately three quarters of curtailment at GB's largest onshore wind farm. It was discussed that market mechanisms need to evolve to allow this. On the basis of the work presented in this paper, the authors suggest the following to be valuable pieces of further work:

1. In a practical controlled charging set-up the charging controller would likely not have access to such detailed information as the leave time and the required energy transfer of each vehicle. Furthermore, while the analysis presented in this paper is based on historic carbon intensity and curtailment data, in practice, any scheduling of charge events would be done on the strength of forecasting. On this basis, it is recommended that further work be undertaken to investigate how such a controlled charging regime could be operated with an imperfect set of information (e.g. based on forecasts of driving behaviour, carbon intensity and curtailment), and what the result would be compared to the "perfect information' example as presented in this paper.

2. Aside from the growth in EVs, there are other opportunities presented from distributed energy resources such as distributed heating, storage and demand side response: the potential of these technologies to contribute towards a flexible energy system that can interact positively with the grid to further enable decarbonisation could be evaluated, in comparison with what was studied in this paper. 
3. Distribution constraints (thermal and voltage) could limit the flexibility available to the transmission system operator from EVs located at the distribution level. A tractable method of modelling distribution network constraints, such as a full AC optimal power flow or an approximation to it as previously discussed in section 5.3, could be developed to schedule large fleets of EVs over networks of millions of nodes. This could be done using a web of cells or a hierarchical structure of passing flow limits from one level (distribution) to the next (transmission) as proposed in [44].

\section{Acknowledgement}

This work has been done through the Engineering and Physical Sciences Research Council (EPSRC) Centre for Doctoral Training on Future Power Networks and Smart Grids at the University of Strathclyde, funded by grant $\mathrm{EP} / \mathrm{L} 015471 / 1$. This work has been further supported by the EPSRC AGILE project (EP/S003088/1) and the Realising Energy Storage Technologies in Low-carbon Energy Systems (RESTLESS) project (EP/N001893/1). Grateful thanks are expressed to SP Energy Networks and Ciaran Higgins for provision of the Glasgow Southside distribution network data, and to Graeme Flett of the Energy Systems Research Unit (ESRU) at the University of Strathclyde for the assistance in integrating the domestic demand model used in this paper.

\section{References}

[1] International Energy Agency, "CO2 Emissions Statistics," 2019. [Online]. Available: http://bit.ly/2l2mK7f

[2] World Health Organization, "9 out of 10 people worldwide breathe polluted air, but more countries are taking action," 2018. [Online]. Available: http://bit.ly/2mgSVzW

[3] Committee on Climate Change, "Net Zero: The UK's contribution to stopping global warming," Tech. Rep., 2019.

[4] World Bank and PRTM Management Consultants Inc, "The China New Energy Vehicles Program," Tech. Rep., 2011. 
[5] M. Åmman, "Government policy and the development of electric vehicles in Japan," Energy Policy, vol. 34, no. 4, pp. 433-443, 2006. [Online]. Available: http://dx.doi.org/10.1016/j.enpol.2004.06.011

[6] Office of Energy Efficiency \& Renewable Energy, "Electric Vehicles: Tax Credits and Other Incentives," 2019. [Online]. Available: http://bit.ly/2HgVUQt

[7] Ifo Institute for Economic Research, "Kohlemotoren, Windmotoren und Dieselmotoren: Was zeigt die CO2 -Bilanz? [Coal engines, wind engines and diesel engines: what is the $\mathrm{CO} 2$ balance?]," Munich, Tech. Rep., 2019. [Online]. Available: http://bit.ly/2mj0CWj

[8] A. Moro and L. Lonza, "Electricity carbon intensity in European Member States: Impacts on GHG emissions of electric vehicles," Transportation Research Part D: Transport and Environment, vol. 64, no. November 2016, pp. 5-14, 2018. [Online]. Available: https://doi.org/10.1016/j.trd.2017.07.012

[9] RAC Foundation, "Spaced Out: Perspectives on parking policy," 2012. [Online]. Available: https://goo.gl/AfPRDD

[10] M. Honarmand, A. Zakariazadeh, and S. Jadid, "Integrated scheduling of renewable generation and electric vehicles parking lot in a smart microgrid," Energy Conversion and Management, vol. 86, pp. 745-755, 2014. [Online]. Available: http://dx.doi.org/10.1016/j.enconman.2014.06.044

[11] T. Zhang, W. Chen, Z. Han, and Z. Cao, "Charging scheduling of electric vehicles with local renewable energy under uncertain electric vehicle arrival and grid power price," IEEE Transactions on Vehicular Technology, vol. 63, no. 6, pp. 2600-2612, 2014. [Online]. Available: http://dx.doi.org/10.1109/TVT.2013.2295591

[12] C. Jin, X. Sheng, and P. Ghosh, "Optimized electric vehicle charging with intermittent renewable energy sources," IEEE Journal on Selected Topics in Signal Processing, vol. 8, no. 6, pp. 1063-1072, 2014. [Online]. Available: http://dx.doi.org/10.1109/JSTSP.2014.2336624

[13] Department for Transport, "The Road to Zero," Tech. Rep. July, 2018. [Online]. Available: http://bit.ly/2mJqfje 
[14] A. Zakariazadeh, S. Jadid, and P. Siano, "Integrated operation of electric vehicles and renewable generation in a smart distribution system," Energy Conversion and Management, vol. 89, pp. 99-110, 2015. [Online]. Available: http://dx.doi.org/10.1016/j.enconman.2014.09.062

[15] C. K. Ekman, "On the synergy between large electric vehicle fleet and high wind penetration - An analysis of the Danish case," Renewable Energy, vol. 36, no. 2, pp. 546-553, 2011. [Online]. Available: http://dx.doi.org/10.1016/j.renene.2010.08.001

[16] S. Bellekom, R. Benders, S. Pelgröm, and H. Moll, "Electric cars and wind energy: Two problems, one solution? A study to combine wind energy and electric cars in 2020 in The Netherlands," Energy, vol. 45, no. 1, pp. 859-866, 2012.

[17] W. P. Schill and C. Gerbaulet, "Power system impacts of electric vehicles in Germany: Charging with coal or renewables?" Applied Energy, vol. 156, no. 2015, pp. 185-196, 2015. [Online]. Available: http://dx.doi.org/10.1016/j.apenergy.2015.07.012

[18] K. Jorgensen, "Technologies for electric, hybrid and hydrogen vehicles: Electricity from renewable energy sources in transport," Utilities Policy, vol. 16, no. 2, pp. 72-79. [Online]. Available: http://dx.doi.org/10.1016/j.jup.2007.11.005

[19] H. Ma, F. Balthasar, N. Tait, X. Riera-Palou, and A. Harrison, "A new comparison between the life cycle greenhouse gas emissions of battery electric vehicles and internal combustion vehicles," Energy Policy, vol. 44, pp. 160-173, 2012. [Online]. Available: http://dx.doi.org/10.1016/j.enpol.2012.01.034

[20] X. Hu, Y. Zou, and Y. Yang, "Greener plug-in hybrid electric vehicles incorporating renewable energy and rapid system optimization," Energy, pp. 971-980. [Online]. Available: http://dx.doi.org/10.1016/j.energy.2016.06.037

[21] National Grid, "Carbon Intensity Forecast Methodology," 2017. [Online]. Available: http://bit.ly/2mO0GOa

[22] Elexon, "Balancing Mechanism Reports Online," https://bit.ly/2qq97ku. 
[23] Western Power Distribution, "Summary of the findings of the Electric Nation smart charging trial," 2019. [Online]. Available: http://bit.ly/218499W

[24] J. Dixon, P. B. Andersen, K. Bell, and C. Træholt, "On the ease of being green: An investigation of the inconvenience of electric vehicle charging," Applied Energy, vol. 258, 2020. [Online]. Available: https://doi.org/10.1016/j.apenergy.2019.114090

[25] Google, "Google Maps," 2019. [Online]. Available: https://www.google.co.uk/maps

[26] UK Data Service, "UK National Travel Survey 2002-2016," 2019. [Online]. Available: https://goo.gl/LgtfDd

[27] G. Flett and N. Kelly, "An occupant-differentiated, higher-order Markov Chain method for prediction of domestic occupancy," Energy and Buildings, vol. 125, pp. 219-230, 2016. [Online]. Available: https://doi.org/10.1016/j.enbuild.2016.05.015

[28] Centre for Time Use Research, "United Kingdom Time Use Survey, 2014-2015." [Online]. Available: https://goo.gl/C6pMF6

[29] F. Marra, G. Y. Yang, C. Træ holt, E. Larsen, C. N. Rasmussen, and S. You, "Demand profile study of battery electric vehicle under different charging options," IEEE Power and Energy Society General Meeting, 2012. [Online]. Available: http://dx.doi.org/10.1109/PESGM.2012.6345063

[30] M. Tabari and A. Yazdani, "An Energy Management Strategy for a DC Distribution System for Power System Integration of Plug-In Electric Vehicles," IEEE Transactions on Smart Grid, vol. 7, no. 2, pp. 659-668, 2016. [Online]. Available: https://doi.org/10.1109/TSG.2015.2424323

[31] M. Gjelaj, S. Hashemi, P. B. Andersen, and C. Træholt, "Grid Services Provision from Batteries within Charging Stations by using a Stochastic Planning Method of the EVs Demand Grid Services Provision from Batteries within Charging Stations by using a Stochastic Planning Method of the EVs Demand," 2019. [Online]. Available: http://bit.ly/2ZHlyVV 
[32] P. Zhang, K. Qian, C. Zhou, B. G. Stewart, and D. M. Hepburn, "A methodology for optimization of power systems demand due to electric vehicle charging load," IEEE Transactions on Power Systems, vol. 27, no. 3, pp. 1628-1636, 2012. [Online]. Available: http://dx.doi.org/10.1109/TPWRS.2012.2186595

[33] S. I. Vagropoulos and A. G. Bakirtzis, "Optimal bidding strategy for electric vehicle aggregators in electricity markets," IEEE Transactions on Power Systems, vol. 28, no. 4, pp. 4031-4041, 2013. [Online]. Available: http://dx.doi.org/10.1109/TPWRS.2013.2274673

[34] W. Kempton, V. Udo, K. Huber, K. Komara, S. Letendre, S. Baker, D. Brunner, and N. Pearre, "A Test of Vehicle-to-Grid (V2G) for Energy Storage and Frequency Regulation in the PJM System: Results from an Industry-University Research Partnership," Tech. Rep., 2008. [Online]. Available: http://bit.ly/2kSTcsz

[35] I. Staffell, "Measuring the progress and impacts of decarbonising british electricity," Energy Policy, vol. 102, pp. 463 - 475, 2017.

[36] The Committee on Climate Change, "The fifth carbon budget: the next step towards a low-carbon economy," Tech. Rep., 2019.

[37] C. Crozier, D. Apostolopoulou, and M. McCulloch, "Mitigating the impact of personal vehicle electrification: A power generation perspective," Energy Policy, vol. 118, pp. 474-481, 2018. [Online]. Available: https://doi.org/10.1016/j.enpol.2018.03.056

[38] National Grid, "Electricity Ten Year Statement 2018," https://bit.ly/2qs7Yc7.

[39] London Economics, "The Value of Lost Load (VoLL) for Electricity in Great Britain: Final report for OFGEM and DECC," London, Tech. Rep., 2013. [Online]. Available: https://bit.ly/2PNAIVR

[40] D. Hirst, "Carbon Price Floor (CPF) and the price support mechanism," Tech. Rep., 2018. [Online]. Available: https://bit.ly/2PIPQUu

[41] W. Bukhsh, C. Edmunds, and K. Bell, "Oats: Optimisation and analysis toolbox for power systems," IEEE Transactions on Power Systems (Accepted/In Press), 2020. 
[42] J. F. Franco, L. F. Ochoa, and R. Romero, "AC OPF for smart distribution networks: An efficient and robust quadratic approach," IEEE Transactions on Smart Grid, vol. 9, no. 5, pp. 4613-4623, 2018. [Online]. Available: http://dx.doi.org/10.1109/TSG.2017.2665559

[43] H. Gerard, E. I. Rivero Puente, and D. Six, "Coordination between transmission and distribution system operators in the electricity sector: A conceptual framework," Utilities Policy, vol. 50, pp. 40-48, 2018. [Online]. Available: https://doi.org/10.1016/j.jup.2017.09.011

[44] K. Bell and S. Gill, "Delivering a highly distributed electricity system: Technical, regulatory and policy challenges," Energy Policy, vol. 113, no. October 2017, pp. 765-777, 2018. [Online]. Available: https://doi.org/10.1016/j.enpol.2017.11.039

[45] C. Edmunds, S. Galloway, I. Elders, W. Bukhsh, and R. Telford, "A DSO-TSO balancing market coordination scheme for the decentralised energy future," IET Generation, Transmission \& Distribution, 2019. [Online]. Available: https://doi.org/5C10.1049/iet-gtd.2019.0865

[46] Transport Scotland, "Scottish Transport Statistics: No. 35 - 2016 Edition," The Scottish Government, Edinburgh, Tech. Rep., 2016. [Online]. Available: https://bit.ly/33kFi3o

[47] House of Commons Business Energy and Industrial Strategy Committee, "Electric vehicles: driving the transition (Fourteenth Report of Session 2017-19)," UK Parliament, London, Tech. Rep., 2018.

[48] EV One Stop, "Wallpod EV charging unit | Type 1 | 16/32 Amp (3.6/7.2kW)." [Online]. Available: https://bit.ly/2Mh1T9O

[49] European Environment Agency, "Average CO2 emissions from new cars and new vans increased in 2018," 2019. [Online]. Available: http://bit.ly/2mo8iXu

[50] European Court of Auditors, "The EU's response to the "dieselgate" scandal," Tech. Rep. February, 2019. [Online]. Available: https://bit.ly/2Sl0tkk

[51] United States Environmental Protection Agency, "Data on Cars used for Testing Fuel Economy." [Online]. Available: https://goo.gl/jwrFQm 
1007

[52] Octopus Energy, "Octopus Go," 2019. [Online]. Available: https://bit.ly/36q393w

[53] Bulb, "Smart Tariff," 2019. [Online]. Available: https://bit.ly/33heHUK

[54] OVO Energy, "EV Everywhere Tariff," 2019. [Online]. Available: https://bit.ly/2PNkrl9

[55] National Grid, "Wider Access to the Balancing Mechanism Roadmap," 2019. [Online]. Available: https://ngrid.com/2BSNyhN

[56] —_, "An Introduction to Project TERRE," 2019. [Online]. Available: https://bit.ly/37KT0PE

[57] — - "Every little helps - big boost for smaller electricity providers," 2019. [Online]. Available: https://ngrid.com/2BSNyhN

[58] Department for Transport, "Decarbonising transport: setting the challenge," Tech. Rep., 2020. [Online]. Available: https://bit.ly/3d4PkKe 